Article

\title{
Synthesis of Novel Symmetrical 1,4-Disubstituted 1,2,3-Bistriazole Derivatives via 'Click Chemistry' and Their Biological Evaluation
}

\author{
Esra Düğdü ${ }^{1, *}$, Dilek Ünlüer ${ }^{1}$, Fatih Çelik ${ }^{1}$, Kemal Sancak ${ }^{1}$, Şengül Alpay Karaoğlu ${ }^{2}$ and \\ Arzu Özel ${ }^{3}$ \\ 1 Department of Chemistry, Karadeniz Technical University, Trabzon 61080, Turkey; \\ dunluer@yahoo.com (D.Ü.); fatih.celik@ktu.edu.tr (F.Ç.); ksancak@ktu.edu.tr (K.S.) \\ 2 Department of Biology, Recep Tayyip Erdoğan University, Rize 53100, Turkey; \\ sengul.karaoglu@erdogan.edu.tr \\ 3 Faculty of Pharmacy, Karadeniz Technical University, Trabzon 61080, Turkey; arzuozenozel@ktu.edu.tr \\ * Correspondence: esradugdu@gmail.com; Tel.: +90-462-377-1781
}

Academic Editor: Derek McPhee

Received: 3 March 2016; Accepted: 11 May 2016; Published: 19 May 2016

\begin{abstract}
A series of symmetric bis-1,2,3-triazole compounds 2-5(a-f) were synthesized as potential antioxidant agents via click chemistry. Their structures were confirmed by ${ }^{1} \mathrm{H}-\mathrm{NMR}$ and ${ }^{13} \mathrm{C}-\mathrm{NMR}$. All of the synthesized compounds were subjected to antioxidant and antimicrobial assays. The antioxidant activity of these compounds (AChE inhibition, DPPH and SOD activities) was evaluated. Compound $\mathbf{2} \mathbf{f}$ was found to show the highest AChE inhibition activity of all compounds, while compound $\mathbf{3 b}$ showed a strong inhibitory effect on DPPH radical and compound $\mathbf{2} \mathbf{a}$ was the most effective of all compounds for SOD activity. All synthesized compounds were found to possess moderate antibacterial activity against the bacteria E. coli and Y.pseudotuberculosis.
\end{abstract}

Keywords: 1,2,3-triazole; 1,3-dipolar cycloaddition; antioxidant activity; antimicrobial activity

\section{Introduction}

$\mathrm{N}$-heterocyclic compounds, especially 1,2,3-triazoles, have received special attention because of their widespread use in the synthetic and medicinal chemistry. 1,2,3-Triazoles are considered as interesting heterocycles due to their important pharmacological activities such as antiprotozoal [1], anticonvulsant, anti-HIV [2,3], antimicrobial, antioxidant [4], antifungal [5-7], antimalarial [8], anticancer [9], antiinflammatory, and antitubercular agents [10,11], etc. There are however very few 1,2,3-triazole-containing molecules on the market or in the last stage of clinical trials. Potential pharmaceuticals based on 1,2,3-triazoles include the anticancer compound carboxy amido triazole (CAI), the $\beta$-lactam antibiotic tazobactum, the cephalosporin cefatrizine, and so on (Figure 1) [12].

Substituted 1,2,3-triazole derivatives have been considered as vital structural functionality units commonly available as versatile building blocks in natural products, dyes, corrosion inhibitors, photo stabilizers, photographic materials and agrochemicals [13,14].

The copper-catalyzed azide-alkyne cycloaddition reaction is known for its high fidelity in the presence of many functional groups and under demanding reaction conditions. The experimental simplicity and high selectivity of this process have been exploited in many applications in synthetic and medicinal chemistry, bioconjugations, materials science and polymer chemistry [15]. The copper(I)-catalyzed reaction sequence which regiospecifically joins azides and terminal acetylenes gives only 1,4-disubstituted 1,2,3-triazoles [16]. The process is experimentally simple and appears to have enormous scope. 
Here we report an efficient synthesis of novel bis-1,2,3-triazole derivatives $\mathbf{2}-\mathbf{5}(\mathbf{a}-\mathbf{f})$ containing alkyl chain bridges via copper-catalyzed click chemistry. In connection with our ongoing programme on the synthesis of bistriazole compounds we were interested in exploring the above cycloaddition reaction where some of the key building blocks contained substituted phenoxy groups. Moreover, we evaluated antioxidant and antimicrobial activity of the products against various microorganisms as 1,2,3-triazole compounds are known to have significant biological activity.

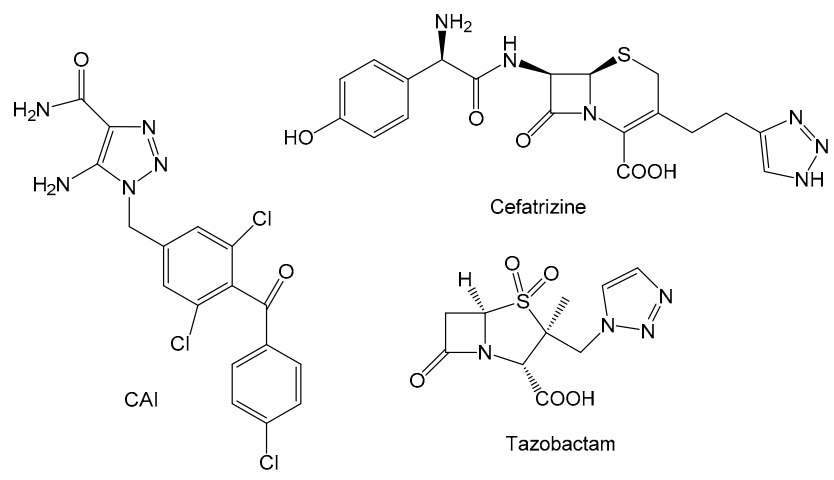

Figure 1. Potential pharmaceuticals based on 1,2,3-triazoles.

\section{Results and Discussion}

The synthesis of the intermediate and target compounds was performed according to the reactions outlined in Scheme 1. As shown, commercially available hydroxy acetophenones or benzaldehydes were subjected to O-alkylation with propargyl bromide in the presence of $\mathrm{K}_{2} \mathrm{CO}_{3}$ in DMF. The starting compounds 2-5 were obtained following a previously reported literature procedure [17]. Then compounds $\mathbf{2}-\mathbf{5}$ were reacted with the bisalkylazide derivatives 1,3-diazido-propane, 1,4-diazidobutane, 1,5-diazidopentane, 1,6-diazidohexane, 1,8-diazidooctane and 1,10-diazidodecane $\left(\left(-\mathrm{CH}_{2}-\right) \mathrm{n}, \mathrm{n}=3,4,5,6,8,10\right)$ under standard "click chemistry" conditions using a copper sulfate pentahydrate/sodium ascorbate system as catalyst, also known as the Huisgen 1,3-dipolar cycloaddition reaction. The reaction conditions in this step are crucial. Because when tert-butyl alcohol/water or ethanol/water solutions were used as solvent this reaction failed to afford the target molecules under these conditions, it was tested with a (1:4) ratio acetone/water solvent system whereby unlike in those solvent systems, the synthesis of the target molecules 2-5(a-f)) was accomplished.

The analytical and spectroscopic data of compounds $\mathbf{2}-\mathbf{5}$ confirmed this by the additional signals derived from the $-\mathrm{CH}_{2} \mathrm{C} \equiv \mathrm{CH}$ groups at the expected chemical shift values. Moreover, compounds 2-5 gave a stable $[\mathrm{M}]^{+}$ion peak. The ${ }^{1} \mathrm{H}-\mathrm{NMR}$ spectra of compounds $\mathbf{2}-\mathbf{5}(\mathbf{a}-\mathbf{f})$ displayed no signals belonging to the $-\mathrm{CH}_{2} \mathrm{C} \equiv \mathrm{CH}$ group; instead, new signals derived from the 1,2,3-triazole structure appeared at 8.13-8.45 ppm (-trz CH) integrating for two protons. Furthermore, compounds 2-5(a-f) gave relatively stable $[\mathrm{M}]^{+}$ion peaks.

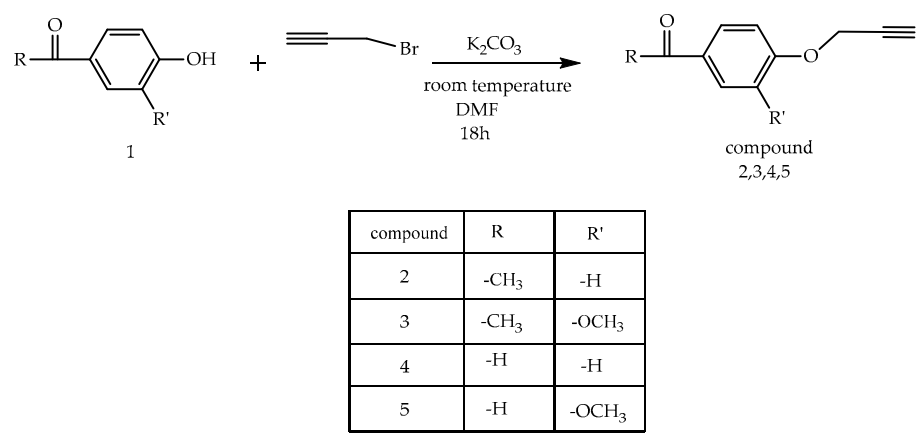

Scheme 1. Cont. 


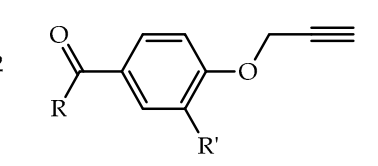

compound

$2,3,4,5$

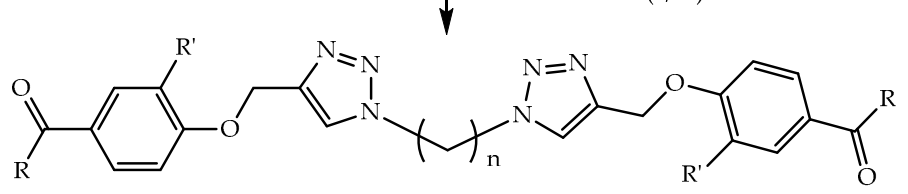

$\left(-\mathrm{CH}_{2}^{-}\right) \mathrm{n}: 3,4,5,6,8,10$

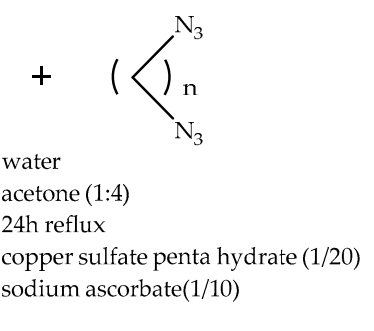

$\mathrm{R}_{\mathrm{O}}$

\begin{tabular}{|l|l|l|l|l|l|l|}
\hline$\left(-\mathrm{CH}_{2}-\right) \mathrm{n}$ & 3 & 4 & 5 & 6 & 8 & 10 \\
\hline compound & $2 \mathrm{a}$ & $2 \mathrm{~b}$ & $2 \mathrm{c}$ & $2 \mathrm{~d}$ & $2 \mathrm{e}$ & $2 \mathrm{f}$ \\
\hline compound & $3 \mathrm{a}$ & $3 \mathrm{~b}$ & $3 \mathrm{c}$ & $3 \mathrm{~d}$ & $3 \mathrm{e}$ & $3 \mathrm{f}$ \\
\hline compound & $4 \mathrm{a}$ & $4 \mathrm{~b}$ & $4 \mathrm{c}$ & $4 \mathrm{~d}$ & $4 \mathrm{e}$ & $4 \mathrm{f}$ \\
\hline compound & $5 \mathrm{a}$ & $5 \mathrm{~b}$ & $5 \mathrm{c}$ & $5 \mathrm{~d}$ & $5 \mathrm{e}$ & $5 \mathrm{f}$ \\
\hline
\end{tabular}

Scheme 1. Synthetic pathway for the preparation of compounds $2-5(a-f)$.

The IR spectra of compounds 2-5(a-f) displayed a new sharp signal at $1600 \mathrm{~cm}^{-1}$ corresponding $\mathrm{C}=\mathrm{C}$ absorptions, while the acetylene peak in $\mathbf{2}-\mathbf{5}$ disappeared. Also different from compounds $\mathbf{2}-\mathbf{5}$ the ${ }^{1} \mathrm{H}-\mathrm{NMR}$ spectra of the target compounds exhibited additional signals due to the 1,2,3-triazole moiety which were observed at $8.13-8.45 \mathrm{ppm}$, the expected chemical shift values. Moreover, the $\mathrm{N}-\mathrm{CH}_{2}$ and $-\mathrm{CH}_{2}$ proton signals belonging to compounds $2-5(\mathbf{a}-\mathbf{f})$ were observed in the $4.33-4.93 \mathrm{ppm}$ range. In the ${ }^{13} \mathrm{C}-\mathrm{NMR}$ spectra of the target compounds the acetylene carbon peaks observed in the $70-80 \mathrm{ppm}$ range disappeared with the formation of 1,2,3-triazole rings, and quaternary carbon peaks were observed in the range of $140-145 \mathrm{ppm}$. In addition, compounds $\mathbf{2}-\mathbf{5}(\mathbf{a}-\mathbf{f})$ gave relatively stable molecular ion peaks in the corresponding mass spectra.

The biological activity results of all the compounds were expressed as $\mathrm{IC}_{50}$ values and are presented as mean \pm S.D. of three independent experiments in Table 1. All of the compounds displayed promising $\mathrm{AChE}$ inhibitory activities, with $\mathrm{IC}_{50}$ values comparable to galantamine used as the reference drug. As can be seen in Table 1 , the $\mathrm{IC}_{50}$ values of all the compounds examined were in the 50.80-88.60 $\mu \mathrm{M}$ range. The $\mathrm{IC}_{50}$ values of the compounds of series $\mathbf{2}, \mathbf{2 a}-\mathbf{2} \mathbf{f}$ indicated remarkable inhibitory activities but all of the rest remained below $70 \mu \mathrm{M}$. Compound $2 \mathrm{f}(50.80( \pm 1.01) \mu \mathrm{M})$ displayed the highest inhibition activity of all compounds. The $\mathrm{IC}_{50}$ values of the compounds of series 3, 3a-3f were below $80 \mu \mathrm{M}$. In this series compound $\mathbf{3 b}$ displayed much higher activity than the other compounds. Compound $4 \mathrm{~d}$ showed important activity in the compound 4 series, while compound $\mathbf{5 e}$ displayed promising inhibitory activity in the $\mathbf{5}$ series.

Some 1,2,3-triazole compounds are known to act either as inhibitors of free radical production or as radical scavengers. Therefore, the potential antioxidant property of the new 1,2,3-trizole compounds was evaluated by determining their DPPH and SOD radical scavenging ability. DPPH is a stable free radical that accepts an electron or hydrogen radical to become a stable species [18]. Due to its odd electron, DPPH gives a strong absorption band at $517 \mathrm{~nm}$. Antioxidants are suitable reducing agents and neutralize the free radicals by pairing the DPPH odd electron with a hydrogen atom, and the DPPH solution turns yellow, observed as the decrease in absorbance at $517 \mathrm{~nm}$ [19]. 
In our study, we evaluated the DPPH scavenging activity of compounds and a standard antioxidant such as BHA as $\mathrm{IC}_{50}$ values (Table 1 and Figure 2). Compound $3 \mathbf{b}$ with an $\mathrm{IC}_{50}$ value of $113.63 \mu \mathrm{g} / \mathrm{mL}$ showed a strong inhibitory effect on DPPH radical. All other compounds showed moderate activities compared to BHA ( $\left.\mathrm{IC}_{50} 98.56 \mu \mathrm{g} / \mathrm{mL}\right)$.

Table 1. $\mathrm{IC}_{50}$ values of the 1,2,3-triazole compounds $\mathbf{2 - 5}(\mathbf{a}-\mathbf{f})$ for AChE inhibition, DPPH and SOD activities.

\begin{tabular}{|c|c|c|c|}
\hline Compound & $\mathrm{AChE} \mathrm{IC}_{50}(\mu \mathrm{M})$ & DPPH IC ${ }_{50}(\mu \mathrm{g} / \mathrm{mL})$ & $\operatorname{SOD~IC~}_{50}(\mu \mathrm{g} / \mathrm{mL})$ \\
\hline $2 \mathbf{a}$ & $64.65( \pm 2.05)$ & $155.49( \pm 0.08)$ & $45.12( \pm 0.04)$ \\
\hline $2 b$ & $52.29( \pm 0.16)$ & $158.72( \pm 0.05)$ & $107.54( \pm 0.07)$ \\
\hline $2 c$ & $67.03( \pm 1.62)$ & $175.65( \pm 0.06)$ & $147.36( \pm 0.05)$ \\
\hline $2 d$ & $62.41( \pm 0.85)$ & $152.84( \pm 0.05)$ & $154.79( \pm 0.06)$ \\
\hline $2 e$ & $66.38( \pm 2.50)$ & $222.16( \pm 0.07)$ & $131.43( \pm 0.06)$ \\
\hline $2 f$ & $50.80( \pm 1.01)$ & $167.51( \pm 0.05)$ & $88.15( \pm 0.06)$ \\
\hline $3 a$ & $63.28( \pm 0.96)$ & $141.57( \pm 0.08)$ & $120.53( \pm 0.04)$ \\
\hline $3 b$ & $56.98( \pm 3.87)$ & $113.63( \pm 0.05)$ & $51.37( \pm 0.07)$ \\
\hline $3 c$ & $75.70( \pm 6.97)$ & $188.45( \pm 0.11)$ & $284.10( \pm 0.07)$ \\
\hline $3 d$ & $75.74( \pm 7.19)$ & $149.21( \pm 0.06)$ & $128.24( \pm 0.10)$ \\
\hline $3 e$ & $56.99( \pm 0.74)$ & $252.68( \pm 0.06)$ & $52.89( \pm 0.06)$ \\
\hline $3 f$ & $78.60( \pm 0.81)$ & $207.57( \pm 0.09)$ & $98.35( \pm 0.06)$ \\
\hline $4 a$ & $62.82( \pm 1.07)$ & $192.02( \pm 0.12)$ & $55.67( \pm 0.08)$ \\
\hline $4 b$ & $74.13( \pm 7.5)$ & $125.05( \pm 0.08)$ & $121.74( \pm 0.08)$ \\
\hline $4 c$ & $83.37( \pm 1.19)$ & $227.38( \pm 0.07)$ & $60.32( \pm 0.07)$ \\
\hline $4 d$ & $58.49( \pm 0.72)$ & $204.31( \pm 0.11)$ & $82.77( \pm 0.11)$ \\
\hline $4 e$ & $63.39( \pm 0.09)$ & $192.04( \pm 0.09)$ & $88.86( \pm 0.09)$ \\
\hline $4 f$ & $62.52( \pm 2.55)$ & $210.33( \pm 0.08)$ & $93.47( \pm 0.09)$ \\
\hline $5 a$ & $74.69( \pm 0.84)$ & $150.03( \pm 0.08)$ & $126.2( \pm 0.07)$ \\
\hline $5 b$ & $61.85( \pm 3.54)$ & $154.51( \pm 0.07)$ & $109.17( \pm 0.10)$ \\
\hline $5 c$ & $69.41( \pm 0.72)$ & $192.46( \pm 0.11)$ & $145.68( \pm 0.11)$ \\
\hline $5 d$ & $70.31( \pm 4.65)$ & $191.39( \pm 0.08)$ & $157.14( \pm 0.07)$ \\
\hline $5 e$ & $61.81( \pm 2.57)$ & $221.57( \pm 0.06)$ & $188.84( \pm 0.08)$ \\
\hline Galantamine & $15.09( \pm 0.01)$ & - & - \\
\hline BHA & - & $98.56( \pm 0.08)$ & - \\
\hline
\end{tabular}

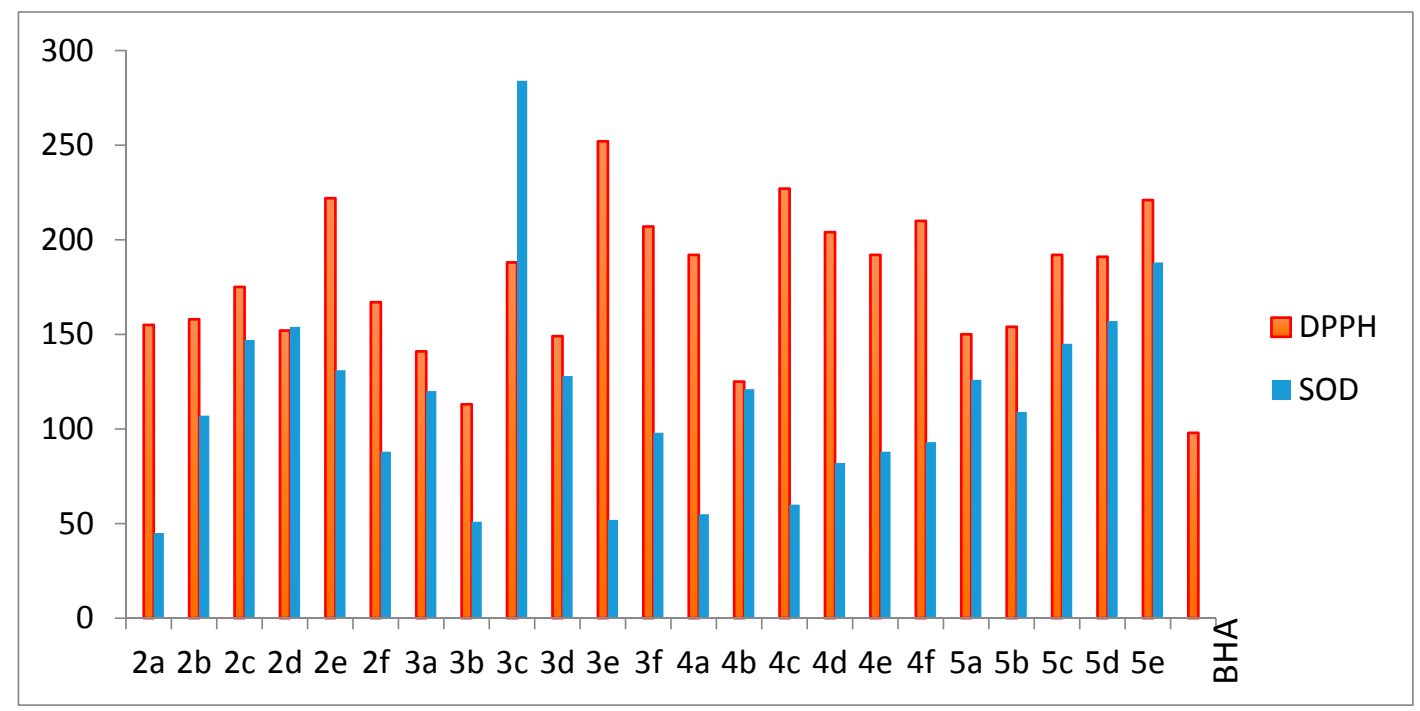

Figure 2. Graphical representation of the antioxidant activity of the tested compounds.

The SOD activity of the compounds was investigated by an NBT assay and the results are shown in Table 1 and Figure 2. Compound $\mathbf{2 a}\left(\mathrm{IC}_{50}=45.12 \mu \mathrm{g} / \mathrm{mL}\right)$ was the most effective of all compounds for 
scavenging superoxide radicals $\left(\mathrm{O}_{2}^{-\bullet}\right)$. Compounds $3 \mathbf{b}\left(\mathrm{IC}_{50}=51.37 \mu \mathrm{g} / \mathrm{mL}\right), 3 \mathbf{e}\left(\mathrm{IC}_{50}=52.89 \mu \mathrm{g} / \mathrm{mL}\right)$ and $4 \mathbf{a}\left(\mathrm{IC}_{50}=55.67 \mu \mathrm{g} / \mathrm{mL}\right)$ also exhibited strong superoxide radical scavenging activity.

All the synthesized compounds were found to possess antibacterial activity against the bacteria E. coli and Y.pseudotuberculosis, which are Gram-negative enteric (intestinal origin) species. In some molecules, antimycotic effects were observed at very low levels against S. cerevisiae and C. albicans yeast. None of the synthesized molecules were observed to have antibacterial activity against Gram negative bacteria ( $P$. aeruginosa), other Gram positive bacteria (B. cereus, S. aureus and E. faecalis) or antitubercular activity against M. smegmatis.

\section{Experimental Section}

\subsection{General Information}

Melting points were measured on an Electrothermal apparatus and are uncorrected. ${ }^{1} \mathrm{H}-\mathrm{NMR}$ and ${ }^{13}$ C-NMR spectra were recorded on an FT-400 NMR spectrophotometer (Agilent, Santa Clara, CA, USA) in DMSO- $d_{6}$. IR spectra were recorded on a Spectrum one FT-IR spectrometer (Perkin-Elmer, Waltham, MA, USA) in KBr pellets. The MS spectra were measured with a Micromass Quattro LC/ULTIMA LC-MS/MS spectrometer (Waters, Milford, MA, USA) with EtOH as solvent. The experiment was performed in the positive ion mode. Elemental analyses were performed on a Hewlett-Packard $185 \mathrm{CHN}$ analyzer (Avondale, PA, USA). All the chemicals were obtained from Fluka Chemie AG (Buchs, Switzerland) and Sigma-Aldrich (St. Louis, MO, USA). Electric eel acetyl-cholinesterase enzyme (AchE, Type-VI-S; EC 3.1.1.7), acetylthiocholine iodide (ATCI), 5,5-dithiobis(2-nitrobenzoic) acid (DTNB), galantamine and 2,2-diphenyl-1-picrylhydrazyl (DPPH), methanol, and Trisma-base were purchased from Sigma-Aldrich and used for the measurement of the acetyl-cholinesterase inhibition and antioxidant activities.

\subsection{Synthesis of Compounds $\mathbf{2}-\mathbf{5}$}

Acetylene derivatives $1(0.010 \mathrm{~mol})$ and potassium carbonate $(0.015 \mathrm{~mol})$ were refluxed in DMF for $1 \mathrm{~h}$. The reaction mixture was cooled to room temperature and propargyl bromide $(0.01 \mathrm{~mol})$ was added and the mixture stirred at room temperature for $24 \mathrm{~h}$. The reaction mixture was poured into $200 \mathrm{~mL}$ of ice-cold water. The solid obtained was washed with water and recrystallized from ethanol to afford the desired title compounds 2-5 [17].

\subsection{General Synthesis Method for the $\mathbf{2}-\mathbf{5}(\mathbf{a}-\mathbf{f})$}

Bisalkylazide derivatives $\left(-\mathrm{CH}_{2}-\right)_{\mathrm{n}}(\mathrm{n}=3,4,5,6,8,10)(0.01 \mathrm{~mol})$ and compounds $2-5(0.02 \mathrm{~mol})$ were stirred in (1:4) water/acetone solution at room temperature for one hour. Then copper sulfate pentahydrate $(1 / 20)$ and sodium ascorbate $(1 / 10)$ were added and the reaction mixture was refluxed for $24 \mathrm{~h}$. At the end of the reaction the flask contents were poured into ice water and a solid was obtained, which was filtered, washed with water and recrystallized from DMF-ethanol to afford the target compounds $\mathbf{2}-\mathbf{5}(\mathbf{a}-\mathbf{f})$.

1,1'-(((Propane-1,3-diylbis(1H-1,2,3-triazole-1,4-diyl))bis(methylene))bis(oxy))bis(4,1-phenylene))bis(ethan-1one) (2a). Yield: 80.02\%; m.p. 181-182 ${ }^{\circ} \mathrm{C}$; IR $\left(v, \mathrm{~cm}^{-1}\right)$ : $1674(\mathrm{C}=\mathrm{O}), 1605$ (C=C), 1255 (C-O); ${ }^{1} \mathrm{H}-\mathrm{NMR}$

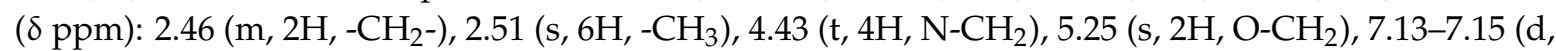
4H, Arom. H), 7.92-7.94 (d, 4H, Arom. H), 8.30 (s, 2H, Arom. -1,2,3-trz. H); ${ }^{13} \mathrm{C}-\mathrm{NMR}(\delta \mathrm{ppm}): 26.85$ $\left(-\mathrm{CH}_{3}\right), 30.61\left(-\mathrm{CH}_{2}-\right), 47.25\left(\mathrm{~N}-\mathrm{CH}_{2}\right), 61.85\left(\mathrm{O}-\mathrm{CH}_{2}\right)$, Arom. C [115.02 (CH), $125.30(\operatorname{trz} . \mathrm{CH}), 130.64$ (C), $130.91(\mathrm{CH}), 142.76$ (trz. C-N), $162.31(\mathrm{C})], 196.76(\mathrm{C}=\mathrm{O})$; Anal. Calcd (\%) for $\mathrm{C}_{25} \mathrm{H}_{26} \mathrm{~N}_{6} \mathrm{O}_{4}(474.20)$ : C, 63.28; H, 5.52; N, 17.71; found: C, 63.22; H, 5.56; N, 17.73; MS (ESI): $m / z(\%) 475.55[\mathrm{M}+1]^{+}$.

1,1'-(((Butane-1,4-diylbis(1H-1,2,3-triazole-1,4-diyl))bis(methylene))bis(oxy))bis(4,1-phenylene))bis(ethan-1one) (2b). Yield: 75.02\%; m.p. $183-184{ }^{\circ} \mathrm{C}$; IR $\left(v, \mathrm{~cm}^{-1}\right)$ : 1677 (C=O), 1600 (C=C),1248 (C-O); ${ }^{1} \mathrm{H}-\mathrm{NMR}$

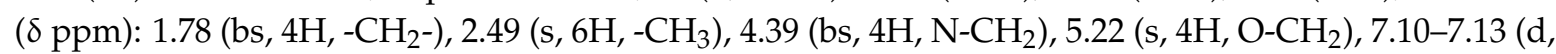


4H, Arom. H), 7.89-7.92 (d, 4H, Arom. H), 8.23 (s, 2H, Arom. -1,2,3-trz. H); ${ }^{13} \mathrm{C}-\mathrm{NMR}(\delta \mathrm{ppm}): 26.07$

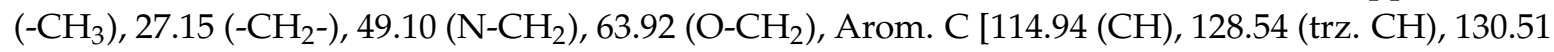
(C), $130.91(\mathrm{CH}), 142.58$ (trz. C-N), $162.38(\mathrm{C})], 196.76(\mathrm{C}=\mathrm{O})$; Anal. Calcd (\%) for $\mathrm{C}_{26} \mathrm{H}_{28} \mathrm{~N}_{6} \mathrm{O}_{4}$ (488.22): C, 63.92; H, 5.78; N, 17.20; found: C, 63.91; H, 5.75; N, 17.21; MS (ESI): $m / z(\%) 527.23[\mathrm{M}+1]^{+}$.

1,1'-((((Pentane-1,5-diylbis(1H-1,2,3-triazole-1,4-diyl))bis(methylene))bis(oxy))bis(4,1-phenylene))bis(ethan-1one) (2c). Yield: $75.02 \%$; m.p. $147-148^{\circ} \mathrm{C}$; IR $\left(v, \mathrm{~cm}^{-1}\right)$ : 1673 (C=O), 1604 (C=C), 1246 (C-O); ${ }^{1} \mathrm{H}-\mathrm{NMR}$ ( $\delta \mathrm{ppm}): 1.20-1.30\left(\mathrm{~m}, 2 \mathrm{H},-\mathrm{CH}_{2}-\right), 1.80-1.85\left(\mathrm{~m}, 4 \mathrm{H},-\mathrm{CH}_{2}-\right), 2.48\left(\mathrm{~s}, 6 \mathrm{H},-\mathrm{CH}_{3}\right), 4.33(\mathrm{bs}, 4 \mathrm{H}$, $\left.\mathrm{N}-\mathrm{CH}_{2}\right), 5.21\left(\mathrm{~s}, 4 \mathrm{H}, \mathrm{O}-\mathrm{CH}_{2}\right), 7.10-7.13(\mathrm{~d}, 4 \mathrm{H}$, Arom. H), 7.89-7.92 (d, 4H, Arom. H), $8.22(\mathrm{~s}, 2 \mathrm{H}$, Arom. -1,2,3-trz. H); ${ }^{13} \mathrm{C}-\mathrm{NMR}(\delta \mathrm{ppm}): 23.20\left(-\mathrm{CH}_{2}-\right), 26.83\left(-\mathrm{CH}_{3}\right), 29.43\left(-\mathrm{CH}_{2}-\right), 49.59\left(\mathrm{~N}^{-} \mathrm{CH}_{2}\right)$, $61.84\left(\mathrm{O}-\mathrm{CH}_{2}\right)$, Arom. C [114.96 (CH), 125.10(trz.CH), $130.56(\mathrm{C}), 130.89(\mathrm{CH}), 141.35$ (trz. C-N), 162.28 (C)], $196.74(\mathrm{C}=\mathrm{O})$; Anal. Calcd (\%) for $\mathrm{C}_{27} \mathrm{H}_{30} \mathrm{~N}_{6} \mathrm{O}_{4}$ (502.23): $\mathrm{C}, 64.53 ; \mathrm{H}, 6.02 ; \mathrm{N}, 16.72$; found: $\mathrm{C}$, 64.50; H, 6.01; N, 16.75; MS (ESI): $m / z(\%) 503.33[\mathrm{M}+1]^{+}$.

1,1'-(((Hexane-1,6-diylbis(1H-1,2,3-triazole-1,4-diyl))bis(methylene))bis(oxy))bis(4,1-phenylene))bis(ethan-1one) (2d). Yield: $78.15 \%$; m.p. $166-167^{\circ} \mathrm{C}$; IR $\left(v, \mathrm{~cm}^{-1}\right)$ : $1677(\mathrm{C}=\mathrm{O}), 1600(\mathrm{C}=\mathrm{C}), 1246(\mathrm{C}-\mathrm{O}) ;{ }^{1} \mathrm{H}-\mathrm{NMR}$

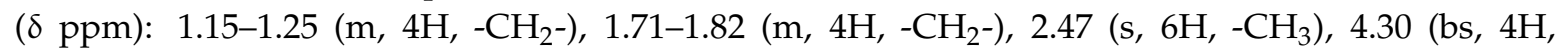

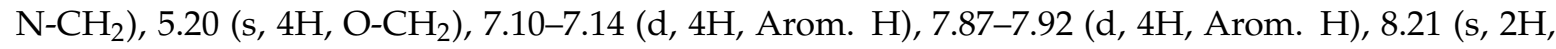
Arom. -1,2,3-trz. H); ${ }^{13} \mathrm{C}-\mathrm{NMR}(\delta \mathrm{ppm}): 25.63\left(-\mathrm{CH}_{2}-\right) 26.82\left(-\mathrm{CH}_{3}\right), 29.87\left(-\mathrm{CH}_{2}-\right), 49.71\left(\mathrm{~N}^{-} \mathrm{CH}_{2}\right)$, $61.84\left(\mathrm{O}-\mathrm{CH}_{2}\right)$, Arom. C [114.98 (CH), 128.45 (trz. CH), $125.48(\mathrm{C}), 130.88(\mathrm{CH}), 142.55$ (trz. C-N), 165.40 (C)], 196.95 (C=O); Anal. Calcd (\%) for $\mathrm{C}_{28} \mathrm{H}_{32} \mathrm{~N}_{6} \mathrm{O}_{4}$ (516.25): C, 65.10; $\mathrm{H}, 6.24 ; \mathrm{N}, 16.27$; found: C, 65.12; H, 6.25; N, 16.25; MS (ESI): $m / z$ (\%) $517.47[\mathrm{M}+1]^{+}$.

1,1'-((((Octane-1,8-diylbis(1H-1,2,3-triazole-1,4-diyl))bis(methylene))bis(oxy))bis(4,1-phenylene))bis(ethan-1one) (2e). Yield: $76.15 \%$; m.p. $169-170{ }^{\circ} \mathrm{C}$; IR $\left(v, \mathrm{~cm}^{-1}\right): 1678(\mathrm{C}=\mathrm{O}), 1601(\mathrm{C}=\mathrm{C}), 1252$ (C-O); ${ }^{1} \mathrm{H}-\mathrm{NMR}(\delta \mathrm{ppm}): 1.16-1.24\left(\mathrm{~m}, 8 \mathrm{H},-\mathrm{CH}_{2}-\right), 1.72-1.81\left(\mathrm{~m}, 4 \mathrm{H},-\mathrm{CH}_{2}-\right), 2.48\left(\mathrm{~s}, 6 \mathrm{H},-\mathrm{CH}_{3}\right), 4.33(\mathrm{bs}$, $\left.4 \mathrm{H}, \mathrm{N}-\mathrm{CH}_{2}\right), 5.21\left(\mathrm{~s}, 4 \mathrm{H}, \mathrm{O}-\mathrm{CH}_{2}\right), 7.10-7.12(\mathrm{~d}, 4 \mathrm{H}$, Arom. H), 7.89-7.91 (d, 4H, Arom. H), $8.22(\mathrm{~s}, 2 \mathrm{H}$, Arom. -1,2,3-trz. H); ${ }^{13} \mathrm{C}-\mathrm{NMR}(\delta \mathrm{ppm}): 26.13\left(-\mathrm{CH}_{2}-\right), 26.83\left(-\mathrm{CH}_{2}-\right), 28.59\left(-\mathrm{CH}_{3}\right), 30.04\left(-\mathrm{CH}_{2}-\right), 49.81$ $\left(\mathrm{N}-\mathrm{CH}_{2}\right), 61.83\left(\mathrm{O}-\mathrm{CH}_{2}\right)$, Arom. C [114.99 (CH), 125.01 (trz. CH), $130.55(\mathrm{C}), 130.87(\mathrm{CH}), 142.38$ (trz. C-N), $162.28(\mathrm{C})], 196.72(\mathrm{C}=\mathrm{O})$; Anal. Calcd (\%) for $\mathrm{C}_{30} \mathrm{H}_{36} \mathrm{~N}_{6} \mathrm{O}_{4}$ (544.28): $\mathrm{C}, 66.16 ; \mathrm{H}, 6.66 ; \mathrm{N}, 15.43$; found: C, 66.18; H, 6.64; N, 15.44; MS (ESI): $m / z$ (\%) $545.14[\mathrm{M}+1]^{+}$.

1,1'-((((Decane-1,10-diylbis(1H-1,2,3-triazole-1,4-diyl))bis(methylene))bis(oxy))bis(4,1-phenylene))bis-(ethan-1one) (2f). Yield: $74.15 \%$; m.p. $165-166{ }^{\circ} \mathrm{C}$; IR $\left(v, \mathrm{~cm}^{-1}\right)$ : 1677 (C=O), $1603(\mathrm{C}=\mathrm{C}), 1251$ (C-O); ${ }^{1} \mathrm{H}-\mathrm{NMR}$ ( $\delta$ ppm): 1.21-1.22 (m, 12H, $\left.-\mathrm{CH}_{2}-\right), 1.81\left(\mathrm{~m}, 4 \mathrm{H},-\mathrm{CH}_{2}-\right), 2.51\left(\mathrm{~s}, 6 \mathrm{H},-\mathrm{CH}_{3}\right), 4.35\left(\mathrm{bs}, 4 \mathrm{H}, \mathrm{N}-\mathrm{CH}_{2}\right), 5.25$ (s, 4H, O-CH $\left.{ }_{2}\right), 7.12-7.14(\mathrm{~d}, 4 \mathrm{H}$, Arom. H), 7.91-7.93 (d, 4H, Arom. H), 8.20 (s, 2H, Arom. -1,2,3-trz. $\mathrm{H}) ;{ }^{13} \mathrm{C}-\mathrm{NMR}(\delta \mathrm{ppm}): 24.48\left(-\mathrm{CH}_{2}-\right), 25.26\left(-\mathrm{CH}_{2}-\right), 27.20\left(-\mathrm{CH}_{2}-\right), 27.92\left(-\mathrm{CH}_{3}\right), 30.78\left(-\mathrm{CH}_{2}-\right), 50.42$ $\left(\mathrm{N}-\mathrm{CH}_{2}\right), 62.25\left(\mathrm{O}-\mathrm{CH}_{2}\right)$, Arom. C [115.67 (CH), 128.42 (trz. CH), $130.30(\mathrm{C}), 130.69(\mathrm{CH}), 142.67$ (trz. C-N), $162.54(\mathrm{C})], 197.65(\mathrm{C}=\mathrm{O})$; Anal. Calcd (\%) for $\mathrm{C}_{32} \mathrm{H}_{40} \mathrm{~N}_{6} \mathrm{O}_{4}$ (572.31): C, 67.11; H, 7.04; N, 14.67; found: $\mathrm{C}, 67.13 ; \mathrm{H}, 7.06 ; \mathrm{N}, 14.64 ; \mathrm{MS}$ (ESI): $m / z(\%) 595.35[\mathrm{M}+\mathrm{Na}]^{+}$.

1-(4-((1-(3-(4-((4-Acetyl-2-methoxyphenoxy)methyl)-1H-1,2,3-triazol-1-yl)propyl)-1H-1,2,3-triazol-4-yl)methoxy)-2-methoxyphenyl)ethan-1-one (3a). Yield: 78.15\%; m.p. 157-159 ${ }^{\circ} \mathrm{C} ; \mathrm{IR}\left(\mathrm{v}, \mathrm{cm}^{-1}\right)$ : $1674(\mathrm{C}=\mathrm{O})$, $1587(\mathrm{C}=\mathrm{C}), 1267(\mathrm{C}-\mathrm{O}) ;{ }^{1} \mathrm{H}-\mathrm{NMR}(\delta \mathrm{ppm}): 2.35-2.45\left(\mathrm{~m}, 8 \mathrm{H},\left(-\mathrm{CH}_{2}\right.\right.$ and $\left.\left.-\mathrm{CH}_{3}\right)\right), 3.79\left(\mathrm{~s}, 6 \mathrm{H},-\mathrm{OCH}_{3}\right)$, $4.42\left(\mathrm{t}, 4 \mathrm{H}, \mathrm{N}-\mathrm{CH}_{2}\right), 5.23\left(\mathrm{~s}, 4 \mathrm{H}, \mathrm{O}-\mathrm{CH}_{2}\right), 7.26-7.29(\mathrm{~d}, 2 \mathrm{H}$, Arom. H), 7.44 (s, 2H, Arom. H), 7.61-7.63 (d, 2H, Arom. H), 8.30 (s, 2H, Arom. -1,2,3-trz. CH); ${ }^{13} \mathrm{C}-\mathrm{NMR}(\delta \mathrm{ppm}): 26.79\left(-\mathrm{CH}_{3}\right), 30.64\left(-\mathrm{CH}_{2}-\right)$, $47.26\left(\mathrm{~N}-\mathrm{CH}_{2}\right), 55.94\left(-\mathrm{OCH}_{3}\right), 62.17\left(\mathrm{O}-\mathrm{CH}_{2}\right)$, Arom. C [110.93 (CH), $112.81(\mathrm{CH}), 123.34(\mathrm{CH}), 125.45$ (trz. CH), 130.73 (C) ,142.71 (trz. C-N), 149.19 (C), 152.16 (C)], 196.85 (C=O); Anal. Calcd (\%) for $\mathrm{C}_{27} \mathrm{H}_{30} \mathrm{~N}_{6} \mathrm{O}_{6}$ (534.22): $\mathrm{C}, 60.66 ; \mathrm{H}, 5.66 ; \mathrm{N}, 15.72$; found: $\mathrm{C}, 60.61 ; \mathrm{H}, 5.63 ; \mathrm{N}, 15.70$; MS (ESI): $\mathrm{m} / \mathrm{z}(\%)$ $557.35[\mathrm{M}+\mathrm{Na}]^{+}$.

1-(4-((1-(4-(4-((4-Acetyl-2-methoxyphenoxy)methyl)-1H-1,2,3-triazol-1-yl)butyl)-1H-1,2,3-triazol-4-yl)-methoxy)2-methoxyphenyl)ethan-1-one (3b). Yield: 76.14\%; m.p. 158-159 ${ }^{\circ} \mathrm{C}$; IR $\left(v, \mathrm{~cm}^{-1}\right): 1654(\mathrm{C}=\mathrm{O}), 1590$ $(\mathrm{C}=\mathrm{C}), 1262(\mathrm{C}-\mathrm{O}) ;{ }^{1} \mathrm{H}-\mathrm{NMR}(\delta \mathrm{ppm}): 1.78-1.80\left(\mathrm{~m}, 4 \mathrm{H},-\mathrm{CH}_{2}-\right), 2.48\left(\mathrm{~s}, 6 \mathrm{H},-\mathrm{CH}_{3}\right), 3.77\left(\mathrm{~s}, 6 \mathrm{H},-\mathrm{OCH}_{3}\right)$, 
$4.39\left(\mathrm{t}, 4 \mathrm{H}, \mathrm{N}-\mathrm{CH}_{2}\right), 5.20\left(\mathrm{~s}, 4 \mathrm{H}, \mathrm{O}-\mathrm{CH}_{2}\right), 7.23-7.25$ (d, 2H, Arom. H), 7.42 (s, 2H, Arom. H), 7.58-7.60 (d, 2H, Arom. H), 8.22 (s, 2H, Arom. -1,2,3-trz. CH); ${ }^{13} \mathrm{C}-\mathrm{NMR}(\delta \mathrm{ppm}): 26.92\left(-\mathrm{CH}_{2}-\right), 30.70\left(-\mathrm{CH}_{3}\right)$,

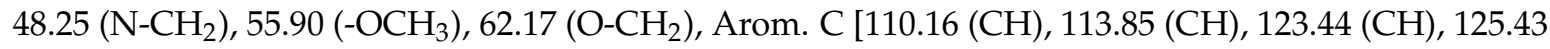
(trz. CH), 130.38 (C) ,142.42 (trz. C-N), 149.74 (C), 153.15 (C)], 196.65 (C=O); Anal. Calcd (\%) for $\mathrm{C}_{28} \mathrm{H}_{32} \mathrm{~N}_{6} \mathrm{O}_{6}$ (548.24): $\mathrm{C}, 61.30 ; \mathrm{H}, 5.88 ; \mathrm{N}, 15.32$; found: $\mathrm{C}, 61.32 ; \mathrm{H}, 5.86 ; \mathrm{N}, 15.34 ; \mathrm{MS}$ (ESI): $\mathrm{m} / z$ (\%) $571.38[\mathrm{M}+\mathrm{Na}]^{+}$.

1-(4-((1-(5-(4-((4-Acetyl-2-methoxyphenoxy)methyl)-1H-1,2,3-triazol-1-yl)pentyl)-1H-1,2,3-triazol-4-yl)-methoxy)2-methoxyphenyl)ethan-1-one (3c). Yield: 74.14\%; m.p. 165-166 ${ }^{\circ} \mathrm{C} ; \mathrm{IR}\left(\mathrm{v}, \mathrm{cm}^{-1}\right): 1668(\mathrm{C}=\mathrm{O}), 1584(\mathrm{C}=\mathrm{C})$, $1261(\mathrm{C}-\mathrm{O}) ;{ }^{1} \mathrm{H}-\mathrm{NMR}(\delta \mathrm{ppm}): 1.21\left(\mathrm{~m}, 2 \mathrm{H},-\mathrm{CH}_{2}-\right), 1.84\left(\mathrm{~m}, 4 \mathrm{H},-\mathrm{CH}_{2}-\right), 2.50\left(\mathrm{~s}, 6 \mathrm{H},-\mathrm{CH}_{3}\right), 3.77(\mathrm{~s}$, $\left.6 \mathrm{H},-\mathrm{OCH}_{3}\right), 4.35\left(\mathrm{t}, 4 \mathrm{H}, \mathrm{N}-\mathrm{CH}_{2}\right), 5.20\left(\mathrm{~s}, 4 \mathrm{H}, \mathrm{O}-\mathrm{CH}_{2}\right), 7.22-7.24(\mathrm{~d}, 2 \mathrm{H}$, Arom. $\mathrm{H}), 7.42(\mathrm{~s}, 2 \mathrm{H}$, Arom. $\mathrm{H})$, 7.57-7.59 (d, 2H, Arom. H), 8.22 (s, 2H, Arom. -1,2,3-trz. CH); ${ }^{13} \mathrm{C}-\mathrm{NMR}(\delta \mathrm{ppm}): 23.25\left(-\mathrm{CH}_{2}-\right)$, $26.73\left(-\mathrm{CH}_{2}-\right), 29.49\left(-\mathrm{CH}_{3}\right), 49.59\left(\mathrm{~N}^{-} \mathrm{CH}_{2}\right), 55.84\left(-\mathrm{OCH}_{3}\right), 62.14\left(\mathrm{O}-\mathrm{CH}_{2}\right)$, Arom. C [110.75 $(\mathrm{CH})$, $112.61(\mathrm{CH}), 123.33(\mathrm{CH}), 125.21$ (trz. $\mathrm{CH}), 130.62(\mathrm{C}), 142.53$ (trz. C-N), $149.11(\mathrm{C}), 152.12(\mathrm{C})], 196.82$ $(\mathrm{C}=\mathrm{O})$; Anal. Calcd (\%) for $\mathrm{C}_{29} \mathrm{H}_{34} \mathrm{~N}_{6} \mathrm{O}_{6}$ (562.25): $\mathrm{C}, 61.91 ; \mathrm{H}, 6.09 ; \mathrm{N}, 14.94$; found; $\mathrm{C}, 61.92 ; \mathrm{H}, 6.10 ; \mathrm{N}$, 14.95; MS (ESI): $m / z$ (\%) $585.35[\mathrm{M}+\mathrm{Na}]^{+}$.

1-(4-((1-(6-(4-((4-Acetyl-2-methoxyphenoxy)methyl)-1H-1,2,3-triazol-1-yl)hexyl)-1H-1,2,3-triazol-4-yl)-methoxy)2-methoxyphenyl)ethan-1-onen (3d). Yield: 72.14\%; m.p. 205-207 ${ }^{\circ} \mathrm{C}$; IR $\left(v, \mathrm{~cm}^{-1}\right)$ : $1667(\mathrm{C}=\mathrm{O}), 1582$ $(\mathrm{C}=\mathrm{C}), 1260(\mathrm{C}-\mathrm{O}) ;{ }^{1} \mathrm{H}-\mathrm{NMR}(\delta \mathrm{ppm}): 1.19-1.24\left(\mathrm{~m}, 4 \mathrm{H},-\mathrm{CH}_{2}-\right), 1.76-1.80\left(\mathrm{~m}, 4 \mathrm{H},-\mathrm{CH}_{2}-\right), 2.50(\mathrm{~s}$, $\left.6 \mathrm{H},-\mathrm{CH}_{3}\right), 3.76\left(\mathrm{~s}, 6 \mathrm{H},-\mathrm{OCH}_{3}\right), 4.32\left(\mathrm{t}, 4 \mathrm{H}, \mathrm{N}-\mathrm{CH}_{2}\right), 5.20\left(\mathrm{~s}, 4 \mathrm{H}, \mathrm{O}-\mathrm{CH}_{2}\right), 7.23-7.25(\mathrm{~d}, 2 \mathrm{H}$, Arom. $\mathrm{H})$, $7.42\left(\mathrm{~s}, 2 \mathrm{H}\right.$, Arom. H), 7.58-7.60 (d, 2H, Arom. H), 8.23 (s, 2H, Arom. -1,2,3-trz. CH); ${ }^{13} \mathrm{C}-\mathrm{NMR}(\delta \mathrm{ppm})$ $\delta: 25.66\left(-\mathrm{CH}_{2}-\right), 26.76\left(-\mathrm{CH}_{2}-\right), 29.91\left(-\mathrm{CH}_{3}\right), 49.72\left(\mathrm{~N}-C H_{2}\right), 55.85\left(-\mathrm{OCH}_{3}\right), 62.13\left(\mathrm{O}_{-} \mathrm{CH}_{2}\right)$, Arom. $\mathrm{C}[110.78(\mathrm{CH}), 112.65(\mathrm{CH}), 123.33(\mathrm{CH}), 125.19$ (trz. $\mathrm{CH}), 130.62(\mathrm{C}), 142.50$ (trz. C-N), $149.12(\mathrm{C})$, $152.12(\mathrm{C})], 196.82(\mathrm{C}=\mathrm{O})$; Anal. Calcd (\%) for $\mathrm{C}_{30} \mathrm{H}_{36} \mathrm{~N}_{6} \mathrm{O}_{6}$ (576.27): $\mathrm{C}, 62.49 ; \mathrm{H}, 6.29 ; \mathrm{N}, 14.57$; found: C, 62.48; H, 6.30; N, 14.59; MS (ESI): $m / z(\%) 599.38[\mathrm{M}+\mathrm{Na}]^{+}$.

1-(4-((1-(8-(4-((4-Acetyl-2-methoxyphenoxy)methyl)-1H-1,2,3-triazol-1-yl)octyl)-1H-1,2,3-triazol-4-yl)methoxy)2-methoxyphenyl)ethan-1-one (3e). Yield: 75.14\%; m.p. 172-174 ${ }^{\circ} \mathrm{C}$; $\operatorname{IR}\left(v, \mathrm{~cm}^{-1}\right)$ : $1669(\mathrm{C}=\mathrm{O}), 1585(\mathrm{C}=\mathrm{C})$, 1266 (C-O); ${ }^{1} \mathrm{H}-\mathrm{NMR}(\delta \mathrm{ppm}): 1.18-1.22\left(\mathrm{~m}, 8 \mathrm{H},-\mathrm{CH}_{2}-\right), 1.75-1.80\left(\mathrm{~m}, 4 \mathrm{H},-\mathrm{CH}_{2}-\right), 2.50\left(\mathrm{~s}, 6 \mathrm{H},-\mathrm{CH}_{3}\right)$, $3.76\left(\mathrm{~s}, 6 \mathrm{H},-\mathrm{OCH}_{3}\right), 4.33\left(\mathrm{t}, 4 \mathrm{H}, \mathrm{N}-\mathrm{CH}_{2}\right), 5.21\left(\mathrm{~s}, 4 \mathrm{H}, \mathrm{O}-\mathrm{CH}_{2}\right), 7.23-7.25(\mathrm{~d}, 2 \mathrm{H}, \mathrm{Arom} . \mathrm{H}), 7.42(\mathrm{~s}, 2 \mathrm{H}$, Arom. H), 7.58-7.60 (d, 2H, Arom. H), 8.23 (s, 2H, Arom. -1,2,3-trz. CH); ${ }^{13} \mathrm{C}-\mathrm{NMR}(\delta \mathrm{ppm}): 26.17$

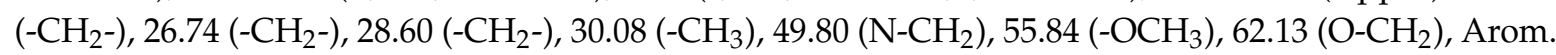
$\mathrm{C}[110.78(\mathrm{CH}), 112.65(\mathrm{CH}), 123.31(\mathrm{CH}), 125.18$ (trz. $\mathrm{CH}), 130.62(\mathrm{C}), 142.49$ (trz. C-N), $149.13(\mathrm{C})$, $152.12(\mathrm{C})], 196.79(\mathrm{C}=\mathrm{O})$; Anal. Calcd (\%) for $\mathrm{C}_{32} \mathrm{H}_{40} \mathrm{~N}_{6} \mathrm{O}_{6}$ (604.30): $\mathrm{C}, 63.56 ; \mathrm{H}, 6.67 ; \mathrm{N}, 13.90$; found: C, 63.58; H, 6.68; N, 13.92; MS (ESI): $m / z$ (\%) $605.31[\mathrm{M}+1]^{+}$.

1-(4-((1-(10-(4-((4-Acetyl-2-methoxyphenoxy)methyl)-1H-1,2,3-triazol-1-yl)decyl)-1H-1,2,3-triazol-4-yl)-methoxy)2-methoxyphenyl)ethan-1-one (3f). Yield: 73.35\%; m.p. 120-122 ${ }^{\circ} \mathrm{C}$; IR $\left(v, \mathrm{~cm}^{-1}\right): 1670(\mathrm{C}=\mathrm{O}), 1587(\mathrm{C}=\mathrm{C})$, $1266(\mathrm{C}-\mathrm{O}) ;{ }^{1} \mathrm{H}-\mathrm{NMR}(\delta \mathrm{ppm}): 1.04-1.18\left(\mathrm{~m}, 12 \mathrm{H},-\mathrm{CH}_{2}-\right), 1.75-1.79\left(\mathrm{~m}, 4 \mathrm{H},-\mathrm{CH}_{2}-\right), 2.50\left(\mathrm{~s}, 6 \mathrm{H},-\mathrm{CH}_{3}\right)$, $3.76\left(\mathrm{~s}, 6 \mathrm{H},-\mathrm{OCH}_{3}\right), 4.33\left(\mathrm{t}, 4 \mathrm{H}, \mathrm{N}-\mathrm{CH}_{2}\right), 5.20\left(\mathrm{~s}, 4 \mathrm{H}, \mathrm{O}-\mathrm{CH}_{2}\right), 7.23-7.25(\mathrm{~d}, 2 \mathrm{H}$, Arom. H), $7.42(\mathrm{~s}, 2 \mathrm{H}$, Arom. H), 7.58-7.60 (d, 2H, Arom. H), 8.23 (s, 2H, Arom. -1,2,3-trz. CH); ${ }^{13} \mathrm{C}-\mathrm{NMR}(\delta \mathrm{ppm}): 26.26$ $\left(-\mathrm{CH}_{2}-\right), 26.76\left(-\mathrm{CH}_{2}-\right), 28.74\left(-\mathrm{CH}_{2}-\right), 29.16\left(-\mathrm{CH}_{2}-\right), 30.14\left(-\mathrm{CH}_{3}\right), 49.83\left(\mathrm{~N}^{-} \mathrm{CH}_{2}\right), 55.86\left(-\mathrm{OCH}_{3}\right), 62.12$ $\left(\mathrm{O}-\mathrm{CH}_{2}\right)$, Arom. C [110.79 (CH), $112.67(\mathrm{CH}), 123.32(\mathrm{CH}), 125.19$ (trz. $\left.\mathrm{CH}\right), 130.62(\mathrm{C}), 142.50$ (trz. C-N), 149.13 (C), $152.12(\mathrm{C})$ ], 196.79 (C=O); Anal. Calcd (\%) for $\mathrm{C}_{34} \mathrm{H}_{44} \mathrm{~N}_{6} \mathrm{O}_{6}$ (632.33): C, 64.54; $\mathrm{H}, 7.01$; $\mathrm{N}, 13.28$; found: $\mathrm{C}, 64.56 ; \mathrm{H}, 7.04 ; \mathrm{N}, 13.29 ; \mathrm{MS}(\mathrm{ESI}): \mathrm{m} / z(\%) 655.24[\mathrm{M}+\mathrm{Na}]^{+}$.

4,4'-(((Propane-1,3-diylbis(1H-1,2,3-triazole-1,4-diyl))bis(methylene))bis(oxy))dibenzaldehyde (4a). Yield: 70.18\%; m.p. $115-116{ }^{\circ} \mathrm{C}$; IR ( $\left.v, \mathrm{~cm}^{-1}\right)$ : $1688(\mathrm{C}=\mathrm{O}), 1598$ (C=C), 1253 (C-O); ${ }^{1} \mathrm{H}-\mathrm{NMR}(\delta \mathrm{ppm})$ : 2.43-2.45 (m, 2H, $\left.-\mathrm{CH}_{2}-\right), 4.43\left(\mathrm{t}, 4 \mathrm{H}, \mathrm{N}-\mathrm{CH}_{2}\right), 5.27\left(\mathrm{~s}, 4 \mathrm{H}, \mathrm{O}-\mathrm{CH}_{2}\right), 7.21-7.23(\mathrm{~d}, 4 \mathrm{H}$, Arom. H) , 7.84-7.86 (d, 4H, Arom. H), 8.30 (s, 2H, Arom. -1,2,3-trz. H), 9.85 (s, 2H, aldehyde-CH); ${ }^{13} \mathrm{C}-\mathrm{NMR}(\delta \mathrm{ppm}): 30.61$ $\left(-\mathrm{CH}_{2}-\right), 47.26\left(\mathrm{~N}-\mathrm{CH}_{2}\right), 61.95\left(\mathrm{O}-\mathrm{CH}_{2}\right)$, Arom. C [115.62 (CH), $125.43($ trz. $\mathrm{CH}), 130.31(\mathrm{C}), 132.22(\mathrm{CH})$, 
143.53 (trz. C-N), 163.38 (C)], 191.74 (aldehyde-CH); Anal. Calcd (\%) for $\mathrm{C}_{23} \mathrm{H}_{22} \mathrm{~N}_{6} \mathrm{O}_{4}$ (446.17): C, 61.88; $\mathrm{H}, 4.97 ; \mathrm{N}, 18.82$; found: $\mathrm{C}, 61.86 ; \mathrm{H}, 4.98 ; \mathrm{N}, 18.84 ; \mathrm{MS}(\mathrm{ESI}): m / z(\%) 469.29[\mathrm{M}+\mathrm{Na}]^{+}$.

4,4'-(((Butane-1,4-diylbis(1H-1,2,3-triazole-1,4-diyl))bis(methylene))bis(oxy))dibenzaldehyde (4b). Yield: 73.53\%; m.p. 154-155 ${ }^{\circ} \mathrm{C}$; IR ( $\left.v, \mathrm{~cm}^{-1}\right)$ : $1682(\mathrm{C}=\mathrm{O}), 1601$ (C=C), 1245 (C-O); ${ }^{1} \mathrm{H}-\mathrm{NMR}(\delta \mathrm{ppm})$ : 1.79 (bs, 4H, $\left.-\mathrm{CH}_{2}-\right), 4.40\left(\mathrm{t}, 4 \mathrm{H}, \mathrm{N}-\mathrm{CH}_{2}\right), 5.25\left(\mathrm{~s}, 4 \mathrm{H}, \mathrm{O}-\mathrm{CH}_{2}\right), 7.20(\mathrm{~s}, 4 \mathrm{H}$, Arom. $\mathrm{H}), 7.84(\mathrm{~s}, 4 \mathrm{H}$, Arom. $\mathrm{H}), 8.24$ (s, 2H, Arom. -1,2,3-trz. H), 9.85 (s, 2H, aldehyde- $\mathrm{CH}) ;{ }^{13} \mathrm{C}-\mathrm{NMR}(\delta \mathrm{ppm}): 27.42\left(-\mathrm{CH}_{2}-\right), 49.20$ $\left(\mathrm{N}-\mathrm{CH}_{2}\right), 61.95\left(\mathrm{O}-\mathrm{CH}_{2}\right)$, Arom. C [115.64 (CH), 125.21 (trz. $\left.\mathrm{CH}\right), 130.31(\mathrm{C}), 132.22(\mathrm{CH}), 142.49$ (trz. C-N), 163.39 (C)], 191.77 (aldehyde-CH); Anal. Calcd (\%) for $\mathrm{C}_{24} \mathrm{H}_{24} \mathrm{~N}_{6} \mathrm{O}_{4}(460.19)$ : C, 62.60; H, 5.25; N, 18.25; found: C, 62.62; H, 5.26; N, 18.27; MS (ESI): $m / z$ (\%) $483.28[\mathrm{M}+\mathrm{Na}]^{+}$.

4,4'-(((Pentane-1,5-diylbis(1H-1,2,3-triazole-1,4-diyl))bis(methylene))bis(oxy))dibenzaldehyde (4c). Yield: 76.73\%; m.p. 98-99 ${ }^{\circ} \mathrm{C}$; IR $\left(v, \mathrm{~cm}^{-1}\right): 1693$ (C=O), $1600(\mathrm{C}=\mathrm{C}), 1243$ (C-O); ${ }^{1} \mathrm{H}-\mathrm{NMR}(\delta \mathrm{ppm}): 1.19-1.21$ $\left(\mathrm{m}, 2 \mathrm{H},-\mathrm{CH}_{2}-\right), 1.81-1.84\left(\mathrm{~m}, 4 \mathrm{H},-\mathrm{CH}_{2}-\right), 4.34\left(\mathrm{t}, 4 \mathrm{H}, \mathrm{N}-\mathrm{CH}_{2}\right), 5.25\left(\mathrm{~s}, 4 \mathrm{H}, \mathrm{O}-\mathrm{CH}_{2}\right), 7.20-7.22(\mathrm{~d}, 4 \mathrm{H}$, Arom. H), 7.84-7.86 (d, 4H, Arom. H), 8.24 (s, 2H, Arom. -1,2,3-trz. H), 9.85 (s, 2H, aldehyde-CH); ${ }^{13} \mathrm{C}-\mathrm{NMR}(\delta \mathrm{ppm}): 23.21\left(-\mathrm{CH}_{2}-\right), 29.45\left(-\mathrm{CH}_{2}-\right), 49.59\left(\mathrm{~N}^{-} \mathrm{CH}_{2}\right), 61.97\left(\mathrm{O}-\mathrm{CH}_{2}\right)$, Arom. C [115.64 (CH), 125.12 (trz. CH), 130.30 (C), 132.22 (CH), 142.41 (trz. C-N), 163.39 (C)], 191.76 (aldehyde-CH); Anal. Calcd (\%) for $\mathrm{C}_{25} \mathrm{H}_{26} \mathrm{~N}_{6} \mathrm{O}_{4}$ (474.20): $\mathrm{C}, 63.28 ; \mathrm{H}, 5.52 ; \mathrm{N}, 17.71$; found: $\mathrm{C}, 63.26 ; \mathrm{H}, 5.53 ; \mathrm{N}, 17.73 ; \mathrm{MS}$ (ESI): $m / z(\%) 475.42[\mathrm{M}+1]^{+}$.

4,4'-(((Hexane-1,6-diylbis(1H-1,2,3-triazole-1,4-diyl))bis(methylene))bis(oxy))dibenzaldehyde (4d). Yield: 76.73\%; m.p. 100-101 ${ }^{\circ} \mathrm{C}$; IR ( $\left.v, \mathrm{~cm}^{-1}\right)$ : $1683(\mathrm{C}=\mathrm{O}), 1608$ (C=C), $1242(\mathrm{C}-\mathrm{O}) ;{ }^{1} \mathrm{H}-\mathrm{NMR}(\delta \mathrm{ppm})$ : 1.21 (bs, $\left.4 \mathrm{H},-\mathrm{CH}_{2}-\right), 1.76\left(\mathrm{bs}, 4 \mathrm{H},-\mathrm{CH}_{2}-\right), 4.32\left(\mathrm{t}, 4 \mathrm{H}, \mathrm{N}-\mathrm{CH}_{2}\right), 5.26\left(\mathrm{~s}, 4 \mathrm{H}, \mathrm{O}-\mathrm{CH}_{2}\right), 7.19-7.21(\mathrm{~d}, 4 \mathrm{H}$, Arom. H), 7.83-7.85 (d, 4H, Arom. H), 8.26 (s, 2H, Arom. -1,2,3-trz. H), 9.84 (s, 2H, aldehyde-CH); ${ }^{13} \mathrm{C}-\mathrm{NMR}(\delta \mathrm{ppm}): 25.63\left(-\mathrm{CH}_{2}-\right), 29.87\left(-\mathrm{CH}_{2}-\right), 49.76\left(\mathrm{~N}-\mathrm{CH}_{2}\right), 62.00\left(\mathrm{O}_{-} \mathrm{CH}_{2}\right)$, Arom. C [115.62 $(\mathrm{CH})$, 130.29 (trz. CH), 132.18 (C) , $132.23(\mathrm{CH}), 142.50$ (trz. C-N), 163.38 (C)], 191.71 (aldehyde-CH); Anal. Calcd (\%) for $\mathrm{C}_{26} \mathrm{H}_{28} \mathrm{~N}_{6} \mathrm{O}_{4}$ (488.22): $\mathrm{C}, 63.92 ; \mathrm{H}, 5.78 ; \mathrm{N}, 17.20$; found: $\mathrm{C}, 63.94 ; \mathrm{H}, 5.77 ; \mathrm{N}, 17.22 ; \mathrm{MS}$ (ESI): $m / z(\%) 489.25[\mathrm{M}+1]^{+}$.

4,4'-(((Octane-1,8-diylbis(1H-1,2,3-triazole-1,4-diyl))bis(methylene))bis(oxy))dibenzaldehyde (4e). Yield: 76.73\%; m.p. 94-95 ${ }^{\circ} \mathrm{C}$; IR $\left(v, \mathrm{~cm}^{-1}\right)$ : 1690 (C=O), 1605 (C=C), 1246 (C-O); ${ }^{1} \mathrm{H}-\mathrm{NMR}(\delta \mathrm{ppm}): 1.17$ (bs, $\left.8 \mathrm{H},-\mathrm{CH}_{2}-\right), 1.76$ (bs, $\left.4 \mathrm{H},-\mathrm{CH}_{2}-\right), 4.33\left(\mathrm{t}, 4 \mathrm{H}, \mathrm{N}-\mathrm{CH}_{2}\right), 5.26\left(\mathrm{~s}, 4 \mathrm{H}, \mathrm{O}-\mathrm{CH}_{2}\right), 7.19-7.21(\mathrm{~d}, 4 \mathrm{H}$, Arom. $\mathrm{H})$, 7.83-7.85 (d, 4H, Arom. H), 8.25 (s, 2H, Arom. -1,2,3-trz. H), 9.85 (s, $2 \mathrm{H}$, aldehyde-CH); ${ }^{13} \mathrm{C}-\mathrm{NMR}$

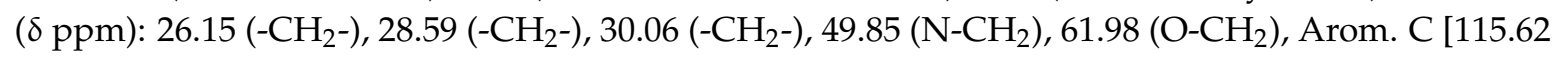
(CH), 125.11 (trz. CH), 130.29 (C), $132.19(\mathrm{CH}), 142.47$ (trz. C-N), 163.39 (C)], 191.66 (aldehyde-CH); Anal.Calcd (\%) for $\mathrm{C}_{28} \mathrm{H}_{32} \mathrm{~N}_{6} \mathrm{O}_{4}$ (516.25): $\mathrm{C}, 65.10 ; \mathrm{H}, 6.24 ; \mathrm{N}, 16.27$; found: $\mathrm{C}, 65.12 ; \mathrm{H}, 6.25 ; \mathrm{N}, 16.28$; MS (ESI): $m / z(\%) 517.14[\mathrm{M}+1]^{+}$.

4,4'-(((Decane-1,10-diylbis(1H-1,2,3-triazole-1,4-diyl))bis(methylene))bis(oxy))dibenzaldehyde (4f). Yield: 74.16\%; m.p. $72-73{ }^{\circ} \mathrm{C}$; IR $\left(v, \mathrm{~cm}^{-1}\right)$ : $1688(\mathrm{C}=\mathrm{O}), 1604(\mathrm{C}=\mathrm{C}), 1250(\mathrm{C}-\mathrm{O}) ;{ }^{1} \mathrm{H}-\mathrm{NMR}(\delta \mathrm{ppm}): 1.36$ (bs, $\left.6 \mathrm{H},-\mathrm{CH}_{2}-\right), 1.95\left(\mathrm{bs}, 4 \mathrm{H},-\mathrm{CH}_{2}-\right), 4.51\left(\mathrm{t}, 4 \mathrm{H}, \mathrm{N}-\mathrm{CH}_{2}\right), 5.43\left(\mathrm{~s}, 4 \mathrm{H}, \mathrm{O}-\mathrm{CH}_{2}\right), 7.38-7.40(\mathrm{~d}, 4 \mathrm{H}$, Arom. $\mathrm{H})$, 8.02-8.04 (d, $4 \mathrm{H}$, Arom. H), 8.43 (s, 2H, Arom. -1,2,3-trz. H), 10.03 (s, 2H, aldehyde-CH); ${ }^{13} \mathrm{C}$ NMR

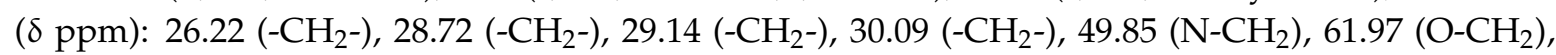
Arom. C [115.65 (CH), 125.11 (trz. CH), $130.28(\mathrm{C}), 132.19(\mathrm{CH}), 142.55$ (trz. C-N), 163.39 (C)], 191.71 (aldehyde-CH); Anal. Calcd (\%) for $\mathrm{C}_{30} \mathrm{H}_{36} \mathrm{~N}_{6} \mathrm{O}_{4}$ (544.28): C, 66.16; $\mathrm{H}, 6.66 ; \mathrm{N}, 15.43$; found: $\mathrm{C}, 66.18$; $\mathrm{H}, 6.68 ; \mathrm{N}, 15.44$; MS (ESI): $m / z(\%) 545.26[\mathrm{M}+1]^{+}$.

4-((1-(3-(4-((4-Formyl-2-methoxyphenoxy)methyl)-1H-1,2,3-triazol-1-yl)propyl)-1H-1,2,3-triazol-4-yl)-methoxy)2-methoxybenzaldehyde (5a). Yield: 82.69\%; m.p. 90-92 ${ }^{\circ} \mathrm{C}$; IR $\left(v, \mathrm{~cm}^{-1}\right): 1676(\mathrm{C}=\mathrm{O}), 1588(\mathrm{C}=\mathrm{C}), 1261$ (C-O); ${ }^{1} \mathrm{H}-\mathrm{NMR}(\delta \mathrm{ppm}): 2.42-2.44\left(\mathrm{~m}, 2 \mathrm{H},-\mathrm{CH}_{2}-\right), 3.78\left(\mathrm{~s}, 6 \mathrm{H},-\mathrm{OCH}_{3}\right), 4.43\left(\mathrm{t}, 4 \mathrm{H}, \mathrm{N}-\mathrm{CH}_{2}\right), 5.25(\mathrm{~s}, 4 \mathrm{H}$, O-CH $\left.{ }_{2}\right), 7.36$ (s, 2H, Arom. H), 7.37-7.39 (d, 2H, Arom. H), 7.52-7.54 (d, 2H, Arom. H), 8.29 (s, 2H, Arom. -1,2,3-trz. H), $9.82\left(\mathrm{~s}, 2 \mathrm{H}\right.$, aldehyde-CH); ${ }^{13} \mathrm{C}-\mathrm{NMR}(\delta \mathrm{ppm}): 30.63\left(-\mathrm{CH}_{2}-\right), 47.25\left(\mathrm{~N}^{\left.-\mathrm{CH}_{2}\right)}, 55.90\right.$ $\left(-\mathrm{OCH}_{3}\right), 62.19\left(\mathrm{O}-\mathrm{CH}_{2}\right)$, Arom. C [110.12 $(\mathrm{CH}), 113.04(\mathrm{CH}), 125.56$ (trz. $\left.\mathrm{CH}\right), 126.28(\mathrm{CH}), 130.37$ 
(C), 142.50 (C), 149.73 (trz. C-N), 153.25 (C)], 191.86 (aldehyde-CH); Anal. Calcd (\%) for $\mathrm{C}_{25} \mathrm{H}_{26} \mathrm{~N}_{6} \mathrm{O}_{6}$ (506.19): C, 59.28; H, 5.17; N, 16.59; found: C, 59.27; H, 5.18; N, 16.57; MS (ESI): $m / z$ (\%) $507.25[\mathrm{M}+1]^{+}$.

4-((1-(4-(4-((4-Formyl-2-methoxyphenoxy)methyl)-1H-1,2,3-triazol-1-yl)butyl)-1H-1,2,3-triazol-4-yl)-methoxy)2-methoxybenzaldehyde (5b). Yield: 79.69\%; m.p. 96-97 ${ }^{\circ} \mathrm{C}$; IR $\left(v, \mathrm{~cm}^{-1}\right): 1665(\mathrm{C}=\mathrm{O}), 1585(\mathrm{C}=\mathrm{C})$, $1263(\mathrm{C}-\mathrm{O}) ;{ }^{1} \mathrm{H}-\mathrm{NMR}(\delta \mathrm{ppm}): 1.80\left(\mathrm{bs}, 4 \mathrm{H},-\mathrm{CH}_{2}-\right), 3.78\left(\mathrm{~s}, 6 \mathrm{H},-\mathrm{OCH}_{3}\right), 4.40\left(\mathrm{t}, 4 \mathrm{H}, \mathrm{N}-\mathrm{CH}_{2}\right), 5.24$ $\left(\mathrm{s}, 4 \mathrm{H}, \mathrm{O}-\mathrm{CH}_{2}\right), 7.37$ (s, 2H, Arom. H), 7.51 (s, 2H, Arom. H), $7.53(\mathrm{~s}, 2 \mathrm{H}$, Arom. H), $8.24(\mathrm{~s}, 2 \mathrm{H}$, Arom. -1,2,3-trz. H), 9.82 (s, 2H, aldehyde-CH); ${ }^{13} \mathrm{C}-\mathrm{NMR}(\delta \mathrm{ppm}): 27.29\left(-\mathrm{CH}_{2}-\right), 49.20\left(\mathrm{~N}^{-\mathrm{CH}_{2}}\right), 55.90$

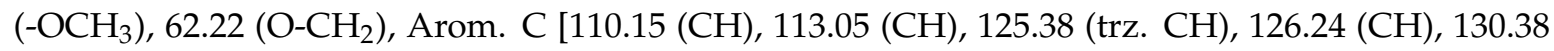
(C), 142.42 (C), 149.74 (trz. C-N), 153.26 (C)], 191.83 (aldehyde-CH); Anal. Calcd (\%) for $\mathrm{C}_{26} \mathrm{H}_{28} \mathrm{~N}_{6} \mathrm{O}_{6}$ (520.21): C, 59.99; H, 5.42; N, 16.14; found: C, 59.98; H, 5.44; N, 16.15; MS (ESI): $m / z$ (\%) $521.23[\mathrm{M}+1]^{+}$.

4-((1-(5-(4-((4-Formyl-2-methoxyphenoxy)methyl)-1H-1,2,3-triazol-1-yl)pentyl)-1H-1,2,3-triazol-4-yl)-methoxy)2-methoxybenzaldehyde (5c). Yield: 88.60\%; m.p. $141-142{ }^{\circ} \mathrm{C}$; IR $\left(v, \mathrm{~cm}^{-1}\right)$ : $1675(\mathrm{C}=\mathrm{O}), 1586(\mathrm{C}=\mathrm{C}), 1261$ (C-O); ${ }^{1} \mathrm{H}-\mathrm{NMR}(\delta \mathrm{ppm}): 1.21\left(\mathrm{~m}, 2 \mathrm{H},-\mathrm{CH}_{2}-\right), 1.82-1.84\left(\mathrm{~m}, 4 \mathrm{H},-\mathrm{CH}_{2}-\right), 3.78\left(\mathrm{~s}, 6 \mathrm{H},-\mathrm{OCH}_{3}\right), 4.34(\mathrm{t}, 4 \mathrm{H}$, $\left.\mathrm{N}-\mathrm{CH}_{2}\right), 5.24\left(\mathrm{~s}, 4 \mathrm{H}, \mathrm{O}-\mathrm{CH}_{2}\right), 7.34(\mathrm{~s}, 2 \mathrm{H}$, Arom. H), 7.35-7.39 (d, 2H, Arom. H), 7.51-7.54 (d, 2H, Arom. $\mathrm{H}), 8.23$ (s, 2H, Arom. -1,2,3-trz. H), 9.82 (s, 2H, aldehyde-CH); ${ }^{13} \mathrm{C}-\mathrm{NMR}(\delta \mathrm{ppm}): 23.25\left(-\mathrm{CH}_{2}-\right), 29.48$ $\left(-\mathrm{CH}_{2}-\right), 49.60\left({\left.\mathrm{~N}-\mathrm{CH}_{2}\right)}^{2}, 55.91\left(-\mathrm{OCH}_{3}\right), 62.24\left(\mathrm{O}-\mathrm{CH}_{2}\right)\right.$, Arom. C [110.10 (CH), $113.01(\mathrm{CH}), 125.30$ (trz. $\mathrm{CH}), 126.26(\mathrm{CH}), 130.36$ (C), 142.34 (C), 149.73 (trz. C-N), 153.27 (C)], 191.82 (aldehyde-CH); Anal. Calcd (\%) for $\mathrm{C}_{27} \mathrm{H}_{30} \mathrm{~N}_{6} \mathrm{O}_{6}$ (534.22): $\mathrm{C}, 60.66 ; \mathrm{H}, 5.66 ; \mathrm{N}, 15.72$; found: $\mathrm{C}, 60.68 ; \mathrm{H}, 5.67 ; \mathrm{N}, 15.73$; MS (ESI): $m / z(\%) 535.36[\mathrm{M}+1]^{+}$.

4-((1-(6-(4-((4-Formyl-2-methoxyphenoxy)methyl)-1H-1,2,3-triazol-1-yl)hexyl)-1H-1,2,3-triazol-4-yl)-methoxy)2-methoxybenzaldehyde (5d). Yield: $68.60 \%$, m.p. $151-152^{\circ} \mathrm{C}$. IR $\left(v, \mathrm{~cm}^{-1}\right): 1681(\mathrm{C}=\mathrm{O}), 1587(\mathrm{C}=\mathrm{C})$, $1262(\mathrm{C}-\mathrm{O}) ;{ }^{1} \mathrm{H}-\mathrm{NMR}(\delta \mathrm{ppm}): 1.23$ (bs, $\left.4 \mathrm{H},-\mathrm{CH}_{2}-\right), 1.77$ (bs, $\left.4 \mathrm{H},-\mathrm{CH}_{2}-\right), 3.77\left(\mathrm{~s}, 6 \mathrm{H},-\mathrm{OCH}_{3}\right), 4.33(\mathrm{t}$, $\left.4 \mathrm{H}, \mathrm{N}-\mathrm{CH}_{2}\right), 5.23\left(\mathrm{~s}, 4 \mathrm{H}, \mathrm{O}-\mathrm{CH}_{2}\right), 7.33-7.35$ (d, 2H, Arom. H), 7.36-7.38 (s, 2H, Arom. H), 7.52-7.54 (s, 2H, Arom. H), 8.24 (s, 2H, Arom. -1,2,3-trz. H), $9.82\left(\mathrm{~s}, 2 \mathrm{H}\right.$, aldehyde-CH); ${ }^{13} \mathrm{C}-\mathrm{NMR}(\delta \mathrm{ppm})$ : $25.65\left(-\mathrm{CH}_{2}-\right), 29.90\left(-\mathrm{CH}_{2}-\right), 49.73\left(\mathrm{~N}^{-C_{2}}\right), 55.90\left(-\mathrm{OCH}_{3}\right), 62.23\left(\mathrm{O}-\mathrm{CH}_{2}\right)$, Arom. C [110.12 $(\mathrm{CH})$, $113.04(\mathrm{CH}), 125.33$ (trz. CH), $126.26(\mathrm{CH}), 130.35$ (C), 142.35 (C), 149.73 (trz. C-N), 153.26 (C)], 191.84 (aldehyde-CH); Anal. Calcd (\%) for $\mathrm{C}_{28} \mathrm{H}_{32} \mathrm{~N}_{6} \mathrm{O}_{6}$ (548.24): C, 61.30; H, 5.88; N, 15.32; found: C, 61.32; $\mathrm{H}, 5.89$; N, 15.34; MS (ESI): $m / z(\%) 549.42[\mathrm{M}+1]^{+}$.

4-((1-(8-(4-((4-Formyl-2-methoxyphenoxy)methyl)-1H-1,2,3-triazol-1-yl)octyl)-1H-1,2,3-triazol-4-yl)-methoxy)2-methoxybenzaldehyde (5e). Yield: 78.60\%; m.p. 144-145 ${ }^{\circ} \mathrm{C}$; IR $\left(v, \mathrm{~cm}^{-1}\right): 1690(\mathrm{C}=\mathrm{O}), 1588(\mathrm{C}=\mathrm{C})$, $1262(\mathrm{C}-\mathrm{O}) ;{ }^{1} \mathrm{H}-\mathrm{MR}(\delta \mathrm{ppm}): 1.05-1.19\left(\mathrm{bs}, 8 \mathrm{H},-\mathrm{CH}_{2}-\right), 1.76\left(\mathrm{~m}, 4 \mathrm{H},-\mathrm{CH}_{2}-\right), 3.77\left(\mathrm{~s}, 6 \mathrm{H},-\mathrm{OCH}_{3}\right), 4.33$ $\left(\mathrm{t}, 4 \mathrm{H}, \mathrm{N}-\mathrm{CH}_{2}\right), 5.24\left(\mathrm{~s}, 4 \mathrm{H}, \mathrm{O}-\mathrm{CH}_{2}\right), 7.34(\mathrm{~s}, 2 \mathrm{H}$, Arom. H), 7.36-7.38 (d, 2H, Arom. H), 7.51-7.52 (d, 2H, Arom. H), 8.24 (s, 2H, Arom. -1,2,3-trz. H), 9.82 (s, 2H, aldehyde-CH); ${ }^{13} \mathrm{C}-\mathrm{NMR}(\delta \mathrm{ppm}): 26.17$ $\left(-\mathrm{CH}_{2}-\right), 28.60\left(-\mathrm{CH}_{2}-\right), 30.08\left(-\mathrm{CH}_{2}-\right), 49.83\left(\mathrm{~N}-C H_{2}\right), 55.87\left(-\mathrm{OCH}_{3}\right), 62.23\left(\mathrm{O}-\mathrm{CH}_{2}\right)$, Arom. C [110.10 (CH), $113.00(\mathrm{CH}), 125.29$ (trz. CH), $126.22(\mathrm{CH}), 130.36$ (C), 142.38 (C), 149.73 (trz. C-N), $153.27(\mathrm{C})]$, 191.77 (aldehyde- $\mathrm{CH}$ ); Anal. Calcd (\%) for $\mathrm{C}_{30} \mathrm{H}_{36} \mathrm{~N}_{6} \mathrm{O}_{6}$ (576.27): C, 62.49; $\mathrm{H}, 6.29 ; \mathrm{N}, 14.57$; found: $\mathrm{C}$, 62.48; H, 6.27; N, 14.56; MS (ESI): $m / z$ (\%) $577.36[\mathrm{M}+1]^{+}$.

4-((1-(10-(4-((4-Formyl-2-methoxyphenoxy)methyl)-1H-1,2,3-triazol-1-yl)decyl)-1H-1,2,3-triazol-4-yl)-methoxy)2-methoxybenzaldehyde (5f). Yield: 69.63\%; m.p. 84-85 ${ }^{\circ} \mathrm{C} ; \mathrm{IR}\left(\mathrm{v}, \mathrm{cm}^{-1}\right): 1679(\mathrm{C}=\mathrm{O}), 1586(\mathrm{C}=\mathrm{C}), 1258$ (C-O); ${ }^{1} \mathrm{H}-\mathrm{NMR}(\delta \mathrm{ppm}): 1.17$ (bs, $\left.12 \mathrm{H},-\mathrm{CH}_{2}-\right), 1.77\left(\mathrm{~m}, 4 \mathrm{H},-\mathrm{CH}_{2}-\right), 3.78\left(\mathrm{~s}, 6 \mathrm{H},-\mathrm{OCH}_{3}\right), 4.33(\mathrm{t}, 4 \mathrm{H}$, $\left.\mathrm{N}-\mathrm{CH}_{2}\right), 5.23\left(\mathrm{~s}, 4 \mathrm{H}, \mathrm{O}-\mathrm{CH}_{2}\right), 7.35(\mathrm{~s}, 2 \mathrm{H}$, Arom. H), 7.36-7.38 (d, 2H, Arom. H), 7.52-7.54 (d, 2H, Arom. $\mathrm{H}), 8.24$ (s, 2H, Arom. -1,2,3-trz. H), $9.82(\mathrm{~s}, 2 \mathrm{H}$, aldehyde- $\mathrm{CH}) ;{ }^{13} \mathrm{C}-\mathrm{NMR}(\delta \mathrm{ppm}): 26.25\left(-\mathrm{CH}_{2}-\right), 28.74$ $\left(-\mathrm{CH}_{2}-\right), 29.15\left(-\mathrm{CH}_{2}-\right), 30.13\left(-\mathrm{CH}_{2}-\right), 49.83\left(\mathrm{~N}^{-} \mathrm{CH}_{2}\right), 55.91\left(-\mathrm{OCH}_{3}\right), 62.22\left(\mathrm{O}-\mathrm{CH}_{2}\right)$, Arom. C [110.12 $(\mathrm{CH}), 113.06(\mathrm{CH}), 125.28$ (trz. $\mathrm{CH}), 126.25(\mathrm{CH}), 130.35(\mathrm{C}), 142.30(\mathrm{C}), 149.74$ (trz. C-N), $153.26(\mathrm{C})]$, 191.82 (aldehyde- $\mathrm{CH}$ ); Anal. Calcd (\%) for $\mathrm{C}_{32} \mathrm{H}_{40} \mathrm{~N}_{6} \mathrm{O}_{6}(604.30): \mathrm{C}, 63.56 ; \mathrm{H}, 6.67 ; \mathrm{N}, 13.90$; found: $\mathrm{C}$, 63.5; H, 6.68; N, 13.92; MS (ESI): $m / z(\%) 605.36[\mathrm{M}+1]^{+}$. 


\subsection{Biological Activity}

\subsubsection{Acetylcholinesterase Inhibition Activity}

Acetylcholinesterase inhibition activity was examined using the method described by Ellman et al. [20] and Inkaninan et al. [21], compared to galantamine as the reference drug. Firstly, all of the compounds stock solution in DMF $\left(1 \times 10^{-3} \mathrm{M}\right)$ were prepared and then five different concentrations were prepared from stock solution in buffer (Tris-HCI pH 8.00) for experiments. Briefly $50 \mu \mathrm{L}$ of $50 \mathrm{mM}$ Tris- $\mathrm{HCl}$ buffer (pH 8.00), $125 \mu \mathrm{L}$ of $3 \mathrm{mM}$ DTNB (in buffer), $25 \mu \mathrm{L}$ of $0.2 \mathrm{U} / \mathrm{mL}$ AChE and $25 \mu \mathrm{L}$ of sample dissolved in buffer and incubated for $15 \mathrm{~min}$. at $25{ }^{\circ} \mathrm{C}$. Fifteen minutes later, $25 \mu \mathrm{L}$ of $15 \mathrm{mM}$ acetyl thiocholine iodide were added and incubated $5 \mathrm{~min}$. at room temperature. The reaction was initiated by the addition of acetylcholine iodide. The hydrolysis of this substrate was monitored by the formation of the yellow 5-thio-2-nitrobenzoate anion as a result of the reaction DTNB with thiocholine, catalized by enzyme at a wave length of $412 \mathrm{~nm}$ using a 96-well microplate reader (Multiskan Go UV-spectrophotometer, Thermo Fisher Scientific Oy Ratastie 2, Vantaa, Finland).

Inhibition of AChE was calculated by the comparison of reaction rates of the samples relative to the blank sample (DMF in phosphate buffer $\mathrm{pH}=8$ ) using the Equation (1) where $\mathrm{A}_{\text {control }}$ is the activity of enzyme without test sample and $\mathrm{A}_{\text {sample }}$ is the activity of enzyme with test sample:

$$
\text { Scavenging effects }(\%)=\left[\frac{\left(\mathrm{A}_{\text {control }}-\mathrm{A}_{\text {sample }}\right)}{\mathrm{A}_{\text {control }}}\right] \times 100
$$

The experiments were carried out in triplicate and $\mathrm{IC}_{50}$ values were examined.

\subsubsection{DPPH Radical Scavenging Assay}

The compounds were tested for in vitro antioxidant activities by the 2,2-diphenyl-1-picrylhydrazyl (DPPH) free radical scavenging assay method [22]. The total volume of the assay mixtures containing methanolic DPPH solution $(0.1 \mathrm{mM})$ and different concentrations of samples was $1 \mathrm{~mL}$. After incubation in the dark at room temperature for $30 \mathrm{~min}$., absorbance of the samples $\left(\mathrm{A}_{\text {sample }}\right)$ was measured at $517 \mathrm{~nm}$. Assay mixture without compound was used as control (control absorbance, $\mathrm{A}_{\text {control }}$ ). All experiments were carried out in triplicate and results were expressed as the mean \pm standard deviation (S.D.). Butylatedhydroxyanisole (BHA) were used as the reference compound. Free radical scavenging effect was calculated using Equation (1).

\subsubsection{Superoxide Radical Scavenging Assay}

Superoxide scavenging activity of the compounds and reference were tested in a non-enzymatic superoxide radical $\left(\mathrm{O}_{2}{ }^{\bullet}\right)$ generation assay using a modified spectrophotometrical nitro blue tetrazolium (NBT) photo reduction method [23]. The total volume of the assay mixtures containing riboflavin $(2 \mu \mathrm{M})$, methionine $(13 \mathrm{mM})$, NBT $(75 \mathrm{mM})$, EDTA $(0.1 \mathrm{mM})$, and the test samples $(50 \mathrm{mM}$ phosphate buffer, $\mathrm{pH}=7.8$ ) was $1 \mathrm{~mL}$. After illuminating with a fluorescent lamp at $30^{\circ} \mathrm{C}$ for $10 \mathrm{~min}$., the absorbance of the samples $\left(\mathrm{A}_{\text {sample }}\right)$ was measured at $560 \mathrm{~nm}$. Assay mixture without the compound was used as control (control absorbance, $\mathrm{A}_{\text {control }}$ ). All experiments were carried out in triplicate and results were expressed as the mean \pm standard deviation (S.D.). Free $\mathrm{O}_{2}{ }^{-\bullet}$ radical scavenging effect was calculated using Equation (1).

\subsection{Antimicrobial Activity}

All test microorganisms were obtained from the Hifzissihha Institute of Refik Saydam (Ankara, Turkey) and were the following: Escherichia coli (E. coli) ATCC25922, Yersinia pseudotuberculosis (Y. pseudotuberculosis) ATCC911, Pseudomonas aeruginosa (P. aeruginosa) ATCC27853, Staphylococcus aureus (S. aureus) ATCC25923, Enterococcus faecalis (E. faecalis) ATCC29212, 
Bacillus cereus (B. cereus) 709ROMA, Mycobacterium smegmatis (M. smegmatis) ATCC607, Candida albicans (C. albicans) ATCC60193 and Saccharomyces cerevisiae (S. cerevisiae) RSKK251. All the extract compounds were dissolved in dimethyl sulphoxide (DMSO) to prepare chemicals stock solution of between 460-632 mg/mL.

A simple susceptibility screening test using the agar-well diffusion method [24] as adapted earlier [25] was used. Each bacterium was suspended in Mueller Hinton (MH) broth (Difco, Detroit, MI, USA). The yeast-like fungi was suspended in yeast extract broth. Then the microorganisms were diluted to approximately $10^{6}$ colony forming unit ( $\mathrm{cfu}$ ) per $\mathrm{mL}$. For yeast-like fungi, potato dextrose agar (PDA, Difco) was used. Brain heart infusion agar (BHI, Difco, Detriot, MI, USA) was used for M. smegmatis. Samples were "flood-inoculated" onto the surface of MH, BHI and SD agars and then dried. Five-millimeter diameter wells were cut from the agar using a sterile cork-borer, and $50 \mu \mathrm{L}$ of the stock extract substances were delivered into the wells. The plates were incubated for $18 \mathrm{~h}$ at $35^{\circ} \mathrm{C}$. The Mycobacterium smegmatis was grown for 3 days on $\mathrm{BHI}$ agar plates at $35^{\circ} \mathrm{C}$ [26]. Antimicrobial activity was evaluated by measuring the zone of inhibition against the test organism. Ampicillin $(10 \mu \mathrm{g})$, streptomycin $(10 \mu \mathrm{g})$ and fluconazole $(5 \mu \mathrm{g})$ were the standard drugs. Dimethyl sulphoxide was used as solvent control. The results are shown in Table 2.

Table 2. Screening for antimicrobial activity of the compounds $(\mu \mathrm{g} / \mu \mathrm{L})$.

\begin{tabular}{ccccccccccc}
\hline \multirow{2}{*}{ Compounds } & $\begin{array}{c}\text { Stock Concentration } \\
(\boldsymbol{\mu g} / \mathbf{m L})\end{array}$ & \multicolumn{7}{c}{ Microorganisms and Inhibition Zone } \\
\cline { 3 - 9 } & $\mathbf{E c}$ & $\mathbf{Y p}$ & $\mathbf{P a}$ & $\mathbf{S a}$ & $\mathbf{E f}$ & $\mathbf{B c}$ & $\mathbf{M s}$ & $\mathbf{C a}$ & $\mathbf{S c}$ \\
\hline $\mathbf{2 a}$ & 474000 & 10 & - & - & - & - & - & - & - & - \\
$\mathbf{2 b}$ & 488000 & 12 & - & - & - & - & - & - & - & - \\
$\mathbf{2 c}$ & 502000 & 12 & - & - & - & - & - & - & 6 & 8 \\
$\mathbf{2 d}$ & 516000 & 12 & - & - & - & - & - & - & 6 & 8 \\
$\mathbf{2 e}$ & 544000 & 12 & - & - & - & - & - & - & - & 6 \\
$\mathbf{2 f}$ & 572000 & 10 & - & - & - & - & - & - & - & 6 \\
$\mathbf{3 a}$ & 534000 & 10 & - & - & - & - & - & - & 6 & 6 \\
$\mathbf{3 b}$ & 548000 & - & - & - & - & - & - & - & - & - \\
$\mathbf{3 c}$ & 562000 & 8 & 6 & - & - & - & - & - & - & - \\
$\mathbf{3 d}$ & 576000 & 8 & 6 & - & - & - & - & - & - & - \\
$\mathbf{3 e}$ & 604000 & 12 & 8 & - & - & - & - & - & - & - \\
$\mathbf{3 f}$ & 632000 & 8 & 6 & - & - & - & - & - & - & - \\
$\mathbf{4 a}$ & 446000 & - & - & - & - & - & - & - & - & - \\
$\mathbf{4 b}$ & 460000 & - & - & - & - & - & - & - & 6 & 6 \\
$\mathbf{4 c}$ & 474000 & 10 & - & - & - & - & - & - & 6 & 6 \\
$\mathbf{4 d}$ & 488000 & - & - & - & - & - & - & - & - & 6 \\
$\mathbf{4 e}$ & 516000 & - & - & - & - & - & - & - & 6 & 6 \\
$\mathbf{4 f}$ & 544000 & 8 & 8 & - & - & - & - & - & - & - \\
$\mathbf{5 a}$ & 506000 & 12 & 8 & - & - & - & - & - & - & - \\
$\mathbf{5 b}$ & 520000 & 10 & 8 & - & - & - & - & - & - & - \\
$\mathbf{5 c}$ & 534000 & 10 & 8 & - & - & - & - & - & - & - \\
$\mathbf{5 d}$ & 548000 & 10 & 8 & - & - & - & - & - & - & - \\
$\mathbf{5 e}$ & 576000 & 10 & 6 & - & - & - & - & - & - & - \\
$\mathbf{5 f}$ & 604000 & 8 & 6 & - & - & - & - & - & - & - \\
& Amp & 10 & 10 & 18 & 10 & 35 & 15 & & & \\
& Strep & & & & & & & 35 & & \\
& Flu. & & & & & & & & 25 & 25 \\
\hline
\end{tabular}

Ec: E. coli ATCC 35218; Yp: Y.pseudotuberculosis ATCC 911; Pa: P. aeruginosa ATCC 10145; Sa: S. aureus ATCC 25923; Ef: E. faecalis ATCC 29212; Bc: B. cereus 709 Roma; Ms: M. smegmatis ATCC607; Ca: C. albicans ATCC 60193; S. cerevisiae RSKK 251; Amp.: Ampicillin; Strep.: Streptomycin; Flu.: Fluconazole; (-): no activity of test concentrations.

\section{Conclusions}

In this study, a series of new bis-1,2,3-triazole derivatives having flexible alkyl chains connected to a phenoxy ring were synthesized and characterized. All spectra of these compounds were submitted 
in the supplementary materials. Antioxidant and antimicrobial assays were performed for all of the synthesized compounds. Biological activity assays (AChE inhibition, DPPH and SOD activities) were performed for all the compounds. Compound $\mathbf{2 f}$ was found to display the highest AChE inhibition activity of all compounds. Compound $\mathbf{3 b}$ showed a strong inhibitory effect on DPPH radicals. All other compounds showed moderate activities compared to BHA. Compound 2a was the most effective of all compounds for SOD activity. The results of this study suggest that 1,2,3-triazole compounds have potential neuroprotective effects due to their acetylcholinesterase inhibition and antioxidant activities. All newly synthesized compounds were screened for their antibacterial activities by the inhibition zone $(\mathrm{mm})$ method. All compounds were found to possess moderately antibacterial activity against the bacteria E. coli, and Y.pseudotuberculosis and antimycotic effects were observed at very low levels against $S$. cerevisiae and C. albicans in some molecules.

Supplementary Materials: Supplementary materials can be accessed at: http:/ /www.mdpi.com/1420-3049/21/ $5 / 659 /$ s1.

Acknowledgments: This was carried out by the research fund of Karadeniz Technical University.

Author Contributions: Esra Düğdü and Kemal Sancak conceived and designed the experiments; Dilek Ünlüer and Fatih Çelik performed the experiments; Şengül Alpay Karaoğlu, Arzu Özel performed the biological experiments and analyzed the data; Esra Düğdü and Fatih Çelik analyzed the spectral data; Esra Düğdü wrote the paper. We also wish to thank Burak BARUT for him help biological experiments.

Conflicts of Interest: The authors declare no conflict of interest.

\section{References}

1. Bakunov, S.A.; Bakunova, S.M.; Wenzler, T.; Ghebru, M.; Werbovetz, K.A.; Brun, R.; Tidwell, R.R. Synthesis and antiprotozoal activity of cationic 1,4-diphenyl-1H-1,2,3-triazoles. J. Med. Chem. 2009, 53, 254-272. [CrossRef] [PubMed]

2. Kelley, J.L.; Koble, C.S.; Davis, R.G. 1-(Fluorobenzyl)-4-amino-1H-1,2,3-triazolo[4,5-c]pyridines: Synthesis and anticonvulsant activity. J. Med. Chem. 1995, 38, 4131-4134. [CrossRef] [PubMed]

3. Li, Q.H.; Ding, Y.; Huang, N.W. Synthesis and biological activities of dithiocarbamates containing 1,2,3-triazoles group. Chin. Chem. Lett. 2014, 25, 1469-1472. [CrossRef]

4. Zhao, X.; Lu, B.W.; Lu, J.R. Design, synthesis and antimicrobial activities of 1,2,3-triazole derivatives. Chin. Chem. Lett. 2012, 23, 933-935. [CrossRef]

5. Vicentini, C.B.; Brandolini, V.; Guarneri, M.; Giori, P. Pyrazolo[3,4- $d][1,2,3]$ triazole-1-carboxamides and 5-alkylaminopyrazolo[3,4-d]oxazoles: Synthesis and evaluation of the in vitro antifungal activity. Farmaco 1992, 47, 1021-1034. [PubMed]

6. Gaur, M.; Goel, M.; Sridhar, L.; Ashok, T.D.S.; Prabhakar, S.; Dureja, P.; Raghunathan, P.; Eswaran, S.V. Synthesis, characterization, and antifungal activity of biaryl-based bis(1,2,3-triazoles) using click chemistry. Mon. Chem. 2012, 143, 283-288. [CrossRef]

7. Su, N.N.; Li, Y.; Yu, S.J.; Zhang, X.; Liu, X.H.; Zhao, W.G. Microwave-assisted synthesis of some novel 1,2,3-triazoles by click chemistry, and their biological activity. Res. Chem. Intermed. 2013, 39, 759-766. [CrossRef]

8. D'Hooghe, M.; Vandekerckhove, S.; Mollet, K.; Vervisch, K.; Dekeukeleire, S.; Lehoucq, L.; Lategan, C.; Smith, P.J.; Chibale, K.; de Kimpe, N. Synthesis of 2-amino-3-arylpropan-1-ols and 1-(2,3-diaminopropyl)-1,2,3-triazoles and evaluation of their antimalarial activity. Beilstein J. Org. Chem. 2011, 7, 1745-1752. [CrossRef] [PubMed]

9. Saikia, B.; Saikia, P.P.; Goswami, A.; Barua, N.C.; Saxena, A.K.; Suri, N. Synthesis of a novel series of 1,2,3-triazole-containing artemisinin dimers with potent anticancer activity involving Huisgen 1,3-dipolar cycloaddition reaction. Synthesis 2011, 19, 3173-3179.

10. Boechat, N.; Ferreira, V.F.; Ferreira, S.B.; Ferreira, M.L.G.; da Silva, F.C.; Bastos, M.M.; Costa, M.S.; Lourenco, M.C.S.; Pinto, A.C.; Krettli, A.U.; et al. Novel 1,2,3-Triazole Derivatives for Use against Mycobacterium tuberculosis H37Rv (ATCC 27294) Strain. J. Med. Chem. 2011, 54, 5988. [CrossRef] [PubMed] 
11. Mubarak, H.S.; Dnyaneshwar, D.S.; Manisha, A.; Vijay, M.K.; Nandadeep, J.; Dhiman, S.; Bapurao, B.S. Synthesis and bioactivity of novel triazole incorporated benzothiazinone derivatives as antitubercular and antioxidant agent. Bioorg. Med. Chem. Lett. 2016, 26, 561-569.

12. Agalave, S.G.; Maujan, S.R.; Pore, V.S. Click chemistry: 1,2,3-triazoles as pharmacop. Chem. Asian J. 2011, 6, 2696-2718. [CrossRef] [PubMed]

13. Fan, W.Q.; Katritzky, A.R. Comprehensive Heterocyclic Chemistry II; Katritzky, A.R., Rees, C.W., Scriven, E.F.V., Eds.; Elsevier Science: Oxford, UK, 1996; Volume 4, pp. 1-126.

14. Kumar, K.K.; Kumar, R.M.; Subramanian, V.; Mohan Das., T. Expedient synthesis of coumarin-coupled triazoles via 'click chemistry' leading to the formation of coumarin-triazole-sugar hybrids. Carbohydr. Res. 2010, 345, 2297-2304. [CrossRef] [PubMed]

15. Hein, J.E.; Tripp, J.C.; Krasnova, L.B.; Sharpless, K.B.; Fokin, V.V. Copper(I)-catalyzed cycloaddition of organic azides and 1-iodoalkynes. Angew. Chem. Int. Ed. 2009, 48, 8018-8021. [CrossRef] [PubMed]

16. Rostovtsev, V.V.; Green, L.G.; Fokin, V.V.; Sharpless, K.B. A Stepwise huisgen cycloaddition process: Copper(I)-catalyzed regioselective "Ligation" of azides and terminal alkynes. Angew. Chem. Int. Ed. 2002, 41, 2708-2711. [CrossRef]

17. Renate, H.H.; Eric, M.G.; Carmen, L.; Peter, J.S.; Baojie, W.; Scott, G.F.; Jiri, G.; Philip, J.R.; Kelly, C. Synthesis, antimalarial and antitubercular activity of acetylenicchalcones. Bioorg. Med. Chem. Lett. 2010, 20, 942-944.

18. Soares, J.R.; Dinis, T.C.P.; Cunha, A.P.; Almeida, L.M. Antioxidant activities of some extracts of Thymuszygis. Free Radic. Res. 1997, 26, 469-478. [CrossRef] [PubMed]

19. Zhou, B.; Li, B.; Yi, W.; Bu, X.; Ma, L. Synthesis, antioxidant, and antimicrobial evaluation of some 2-arylbenzimidazole derivatives. Bioorg. Med. Chem. Lett. 2013, 23, 3759-3763. [CrossRef] [PubMed]

20. Ellman, G.L.; Courtney, K.D.; Andres, V.; Featherstone, R.M. A new andrapid colorimetric determination of acetylcholinesterase activity. Biochem. Pharmacol. 1961, 7, 88-95. [CrossRef]

21. Ingkaninan, K.; Best, D.; Heijden, V.D.; Hofte, A.J.P.; Karabatak, B.; Irth, H.; Tjaden, U.R.; Greef, V.D.; Verpoorte, R. High-performance liquid chromatography with on-linecoupled UV, mass spectrometric and biochemical detection for identification of acetylcholinesterase inhibitors from natural products. J. Chromatogr. 2000, 872, 61-73. [CrossRef]

22. Sharma, S.D.; Rajor, H.K.; Chopra, S.; Sharma, R.K. Studies on structure activity relationship of some dihydroxy-4-methyl coumarin antioxidants based on their interaction with Fe(III) and ADP. Biometals 2005, 18, 143-154. [CrossRef] [PubMed]

23. Blois, M.S. Antioxidant determinations by the use of a stable free radical. Nature 1958, 181, 1199-1200. [CrossRef]

24. Perez, C.; Pauli, M.; Bazerque, P. An antibiotic assay by the well agar method. Acta Biol. Med. Exp. 1990, 15, 113-115.

25. Ahmad, I.; Mehmood, Z.; Mohammed, F. Screening of some Indian medicinal plants for their antimicrobial properties. J. Ethnopharmcol. 1998, 62, 183-193. [CrossRef]

26. Woods, G.L.; Brown-Elliott, B.A.; Desmond, E.P.; Hall, G.S.; Heifets, L.; Pfyffer, G.E.; Ridderhof, J.C.; Wallace, R.J.; Warren, N.C.; Witebsky, F.G. Susceptibility testing of mycobacteria, nocardiae, and other aerobic actinomycetes; Approved Standard. NCCLS Doc. M24-A 2003, 18, 20-31.

Sample Availability: Not Available.

(C) 2016 by the authors; licensee MDPI, Basel, Switzerland. This article is an open access article distributed under the terms and conditions of the Creative Commons Attribution (CC-BY) license (http://creativecommons.org/licenses/by/4.0/). 